\title{
Solid or shell finite elements to model thick cylindrical tubes and shells under global bending
}

\author{
A.J. Sadowski ${ }^{1} \&$ J.M. Rotter ${ }^{2}$
}

\begin{abstract}
This paper explores the use of solid continuum finite elements and shell finite elements in the modelling of the nonlinear plastic buckling behaviour of cylindrical metal tubes and shells under global bending. The assumptions of shell analysis become increasingly uncertain as the ratio of the radius of curvature to the thickness becomes smaller, but the classical literature does not draw a clear line to define when a shell treatment is inappropriate and a continuum model becomes essential. This is a particularly important question for the bending of tubular members, pipelines, chimneys, piles, towers and similar structures. This study is therefore concerned solely with the uniform bending of thin tubes or thick shells which fail by plastic buckling well into the strain-hardening range. The analyses employ finite element formulations available in the commercial software ABAQUS because this is the most widely used tool for parametric research studies in this domain with an extensive and diverse element library. The results are of general validity and are applicable to other finite element implementations. This paper thus seeks to determine the adequacy of a thin or thick shell approximation, taking into account geometric nonlinearity, complex equilibrium paths, limit points and bifurcation buckling, extensive material ductility and linear strain hardening. It aims to establish when it is viable to employ shell elements and when this decision will lead to outcomes that lack sufficient precision for engineering design purposes.
\end{abstract}

The results show that both thin and thick (shear-flexible) shell elements may give a reasonably accurate prediction of the buckling moment under global uniform bending for cylindrical tubes as thick as $R / t=10$. A finite strain and thick shell formulation are additionally shown to model the ductility of such thick tubes well, even when ovalisation of the cross-section and strain hardening are included. The use of solid 
Published in: International Journal of Mechanical Sciences, 74, 143-153.

DOI: http://dx.doi.org/10.1016/j.ijmecsci.2013.05.008

continuum elements to model tubes in bending is found to become increasingly uneconomical as the $R / t$ ratio rises above 25 with reduced advantages over shell elements, both in terms of the accuracy of the solution and the computation time.

\section{Keywords}

Shell finite elements, continuum solid finite elements, plasticity, strain hardening, thick cylindrical shells, bending.

${ }^{1}$ Lecturer, Imperial College London, UK

${ }^{2}$ Professor of Civil Engineering, The University of Edinburgh, UK 
Published in: International Journal of Mechanical Sciences, 74, 143-153.

DOI: http://dx.doi.org/10.1016/j.ijmecsci.2013.05.008

\section{Introduction}

Thin-walled shell theory is characterised by fundamental assumptions which allow shell structures to be analysed in an efficient manner by effectively reducing the dimensions of the problem from three to two. Bushnell [1] summarises the familiar assumptions behind 'thin' or 'first-order' plate/shell theory, also known as KirchhoffLove theory [2-5], as follows:

I. Normals to the shell reference surface remain straight after deformation.

II. Normals to the shell reference surface remain normal after deformation.

III. The transverse normal stress is negligible.

Further, though sometimes not specifically stated, this formulation also assumed that the strains are small compared with unity [6,7] and that the shell thickness is unchangeable (i.e. that the Poisson out-of-plane thickness changes can be ignored). A 'thick' or 'second-order' plate/shell theory is obtained by discarding Assumption II above, taking transverse shear deformation into account, and is known as MindlinReissner theory [8,9]. Progressively higher-order theories are obtained by additionally discarding first Assumption I and then III, leading to a full three-dimensional continuum theory with explicit modelling of all stress and strain components and changes of thickness (e.g. [10-13]).

A decision on the choice between a thin or thick shell approximation or a full threedimensional analysis is not straightforward, since it depends strongly on the context. Flügge [14] suggested that "the shell thickness $t$ should be small" compared to its other dimensions. Timoshenko and Woinowsky-Krieger [15] wrote that thin shell theory is not rigorous enough when the thickness of a shell is "comparable to its radius of curvature $R$ " and that thick shell theory, or a full three-dimensional analysis, should be applied instead. Heyman [77] suggested that the term 'thin shell' refers to those with $R / t>20$. Brush and Almroth [6] wrote simply that $R / t>>1$ for thin shell theory to apply. Bushnell [16] made a similar recommendation while Calladine [5] put a value on this limit, suggesting that shells as thick as $R / t=10$ may be suitable for a "thin shell" treatment. The theory manual of the widely used ABAQUS [17] finite element software recommends the application of transverse shear-flexible 'thick' shell elements when the thickness is "more than about 1/15 of a characteristic length on the surface of the shell", which has multiple possible interpretations (e.g. $R$ or $\sqrt{R t}$ or $2.4 \sqrt{R t}$ ) and 
Published in: International Journal of Mechanical Sciences, 74, 143-153.

DOI: http://dx.doi.org/10.1016/j.ijmecsci.2013.05.008

so is slightly unclear. Many other classical guidelines exist and each is similarly vague.

The above ideas are all loosely based on order-of-magnitude assessments of analytical solutions to relatively simple linear-elastic problems and it is clear that all attempt to give advice, rather than a firm rule. The present paper seeks to establish the validity of a shell theory approximation for the specific and practically important problem of thick cylindrical shells or thin tubular members (radius to thickness ratio $R / t \leq 50$ ) of medium length (length to radius ratio $L / R=7$ ) subject to global bending. This configuration is significantly more complex than the elastic cases often considered in classical texts, and includes geometric nonlinearity with local bending effects, extensive material plasticity, strain hardening, and both limit point and bifurcation buckling. This problem is an important and well-understood classical benchmark against which different theoretical analyses and modelling techniques may be tested.

Since cylinders even thicker than those of this study are used as tubular structural members, those studied here are termed "thin tubes". By contrast, most of the literature on cylindrical shells is concerned with much thinner structures than are studied here, so the same cylinders are here termed "thick shells". These two terms are used here to refer to the same structure. This paper forms part of a study that seeks to resolve the mismatches that currently exist between these two descriptions of the same item.

\section{Behaviour of thick shells under global bending}

When a bending moment is applied to the ends of a cylindrical tube or shell, the end cross-section rotates in the sense of the moment, inducing axial membrane compression on one side of the tube and corresponding tension on the opposite side. The system has two stable equilibrium paths, shown in Fig. 1 in terms of the applied end moment $M$ (normalised by the full plastic moment $M_{p}$ ) against the end rotation $\theta$. The primary path is elastic and close to linear until a moment approaching approximately $0.83 M_{\mathrm{p}}$ (the first yield moment $M_{y}$ ), after which inelastic strains develop and the tangent stiffness decreases significantly. In the thicker tubes (approximately $R / t<50$ ), the response remains almost geometrically linear up to $M_{p}$. If a 
Published in: International Journal of Mechanical Sciences, 74, 143-153.

DOI: http://dx.doi.org/10.1016/j.ijmecsci.2013.05.008

geometrically linear elastic-plastic numerical analysis (termed MNA) is used to continue on this path, the analysis predicts indefinite strain hardening, but naturally there can be no loss of stability. A geometrically nonlinear elastic-plastic numerical analysis (termed GMNA) predicts that significant ovalisation occurs after $M_{p}$ has been exceeded, producing two causes for the loss of tangent stiffness until a limit point is reached [18-22]. This limit point corresponds to a snap-through buckle, and may be followed by a bifurcation in the post-buckling regime (Fig. 1). The possibility of ovalisation causing elastic snap-through buckling, known as the Brazier effect $[5,23,24]$, is only appropriate to very long cylinders, and thick tubes fail by plastic collapse before they reach the critical Brazier moment. The plastic collapse of very thick cylinders involves extensive material straining, and this poses a significant challenge for many finite element models.

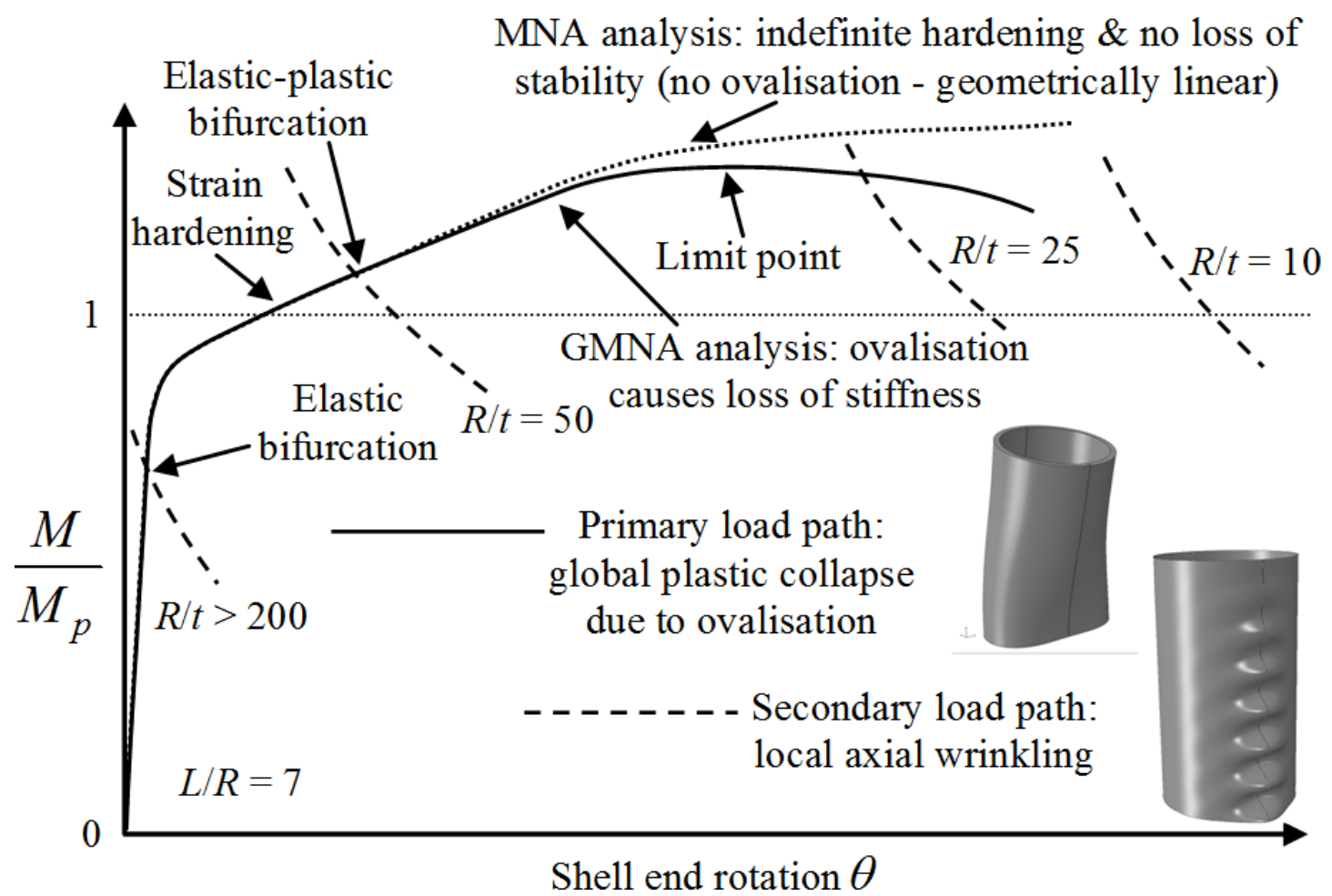

Fig. 1 - Qualitative illustration of the equilibrium paths in cylinders with $L / R=7$ and a strain hardening material law (cylinders of different length exhibit similar qualitative features)

Following a possible bifurcation, a secondary path may produce localised axial wrinkles on the compressed side. The point of bifurcation is strongly dependent on the $R / t$ ratio. If the tube is very thick, the response follows the primary ovalisation path 
Published in: International Journal of Mechanical Sciences, 74, 143-153.

DOI: http://dx.doi.org/10.1016/j.ijmecsci.2013.05.008

past the limit point to large deformations without bifurcating [25-27]. In slightly thinner cylinders, bifurcation may occur after the limit point, but for cylinders thinner than $R / t=50$, bifurcation onto the secondary path occurs before the limit point is reached and the tube exhibits elastic-plastic bifurcation. Perfect cylinders with $R / t>$ 200 suffer elastic bifurcation buckling [18,28,29,30,31,32]. The issue of wrinkling following bifurcation is important for a finite element model because it involves high local shell curvatures, so the elements must be able to accommodate these.

\section{Finite element modelling of thick shells under global bending}

A large body of research exists on the computational modelling of cylindrical tubes in bending, as it has wide applications in many engineering situations. Early work on numerical solutions to the nonlinear ovalisation aspect of tubes in bending may be traced back to Ades [33], Reissner [34], Axelrad [35], Kempner and Chen [36], Kedward [37] and others, but finite element formulations arguably appeared some time later. For example, Row et al. [26] presented a two-dimensional finite element for the analysis of thick-walled cylinders in the context of deep-water pipelines. Karamanos and Tassoulas [27] employed specialised nonlinear 'tube elements' based on a finite strain formulation by Needleman [38] enhanced with the $J_{2}$-flow theory of plasticity (von Mises yield criterion [39]) to study the elastic-plastic behaviour of tubes under both external pressure and bending, with the results being in very good agreement with experimental data [40]. Kyriakides and $\mathrm{Ju}[30,41]$ analysed the inelastic response of aluminium tubes in bending using experiments and numerical studies assuming their own small-strain $J_{2}$-flow plasticity theory shell finite element formulation and exact modelling of circular geometries, with excellent agreement between the two. Karamanos and Tassoulas [42,43] compared numerical predictions of local elasticplastic buckling for thick tubes with $R / t=21$ and $L / R=20$ under bending using similar 'tube elements' with experimental data, also successfully. More recently, Karamanos and Houliara [31,44,45] studied the elastic bifurcation buckling behaviour of long thinwalled tubes under bending $(R / t>100$ and 'infinite' $L / R)$ using a similar 'tube element' formulation. Though successful, the numerical formulations presented in these publications are highly specialised and effectively beyond the reach of practising engineers and most researchers, who generally rely on commercially available finite element software. 
Published in: International Journal of Mechanical Sciences, 74, 143-153.

DOI: http://dx.doi.org/10.1016/j.ijmecsci.2013.05.008

In recent years, several studies emerged on the elastic-plastic behaviour of tubes under combined bending and internal pressure in relation to buried pipelines. These involved experiments but extended the knowledge base with extensive finite element analyses using ABAQUS. They key effect of internal pressure is that it stabilises the tube and usually pushes bifurcation buckling into the plastic material range. In particular, Jayadevan et al. [46] and Østby et al. [47] studied the large plastic deformation behaviour of very thick tubes with $R / t=10$ under tension and bending respectively in the context of the fracture response of pipelines using the reduced-integration second order ABAQUS C3D20R solid continuum element and an isotropic power-law strain hardening material model. Further, Corona et al. [48] applied the fully-integrated second order ABAQUS C3D27 solid continuum element to model thick tubes with $R / t$ $\approx 18$ under bending using an elastic-plastic Ramberg-Osgood [49] strain hardening material model. Limam et al. [50] used the fully-integrated first order ABAQUS S4 thick shell element with a similar strain hardening model based on a Ramberg-Osgood empirical fit to measured material properties. They successfully reproduced experimental moment-curvature curves for pressurised shells as thick as $R / t \approx 26$ with $L / R$ ranging from 22 to 34 . Lastly, Limam et al. [51] modelled similarly thick shells with $L / R=10$ using instead the fully-integrated first order ABAQUS C3D8 solid continuum element and obtained the same degree of success in reproducing experimental results.

The abovementioned studies suggest that an accurate modelling of the plastic material response is crucial for thick cylinders under global bending. Together, these authors showed conclusively that both the shell and solid theoretical treatments may be used successfully to model the buckling of tubes with realistic, large strain, inelastic material behaviour. Although these studies partially addressed the same topic as is covered by the work presented here, they gave little justification for their choice of theory and did not investigate whether a solid or shell element was necessary in each case. The apparent bias towards ABAQUS is purely coincidental, and the authors are not aware of any published computational studies of tubes in bending which use other commercial finite element software. 
Published in: International Journal of Mechanical Sciences, 74, 143-153.

DOI: http://dx.doi.org/10.1016/j.ijmecsci.2013.05.008

The present paper is an attempt to provide rigorous numerical evidence to aid in the selection of an appropriate finite element by comparing the predicted nonlinear plastic buckling behaviours of thick and thin tubes under global bending when modelled using several solid continuum finite elements and several shell elements. Three different radius to thickness $(R / t)$ ratios were chosen: 10,25 and 50 . The ratio $R / t=10$ is a tube so thick that shell theory may be thought quite inappropriate (see initial discussion), while $R / t=50$ should be well within the range where a thin shell treatment has traditionally been thought to be acceptable. The cylinder was assumed to be of medium length with $L / R=7$, of sufficient length for the local shell bending effects near the end boundaries to have little influence on the result $[22,32,46,47]$.

\section{Numerical treatment used in this study}

Three cylindrical tubes with radius to thickness $(R / t)$ ratios of 10,25 and 50 were modelled using finite elements corresponding to thick and thin shell and solid continuum theoretical treatments. All analyses were undertaken using geometrically and materially nonlinear analysis (GMNA), as defined in the European Standard on shell buckling EN 1993-1-6 [52], to fully capture distortions, ovalisation and bifurcations. To provide relatively generic conclusions, the material properties were taken as a characterised version of the uniaxial tensile behaviour of a mild isotropic steel (Fig. 2), with elastic modulus $E=200 \mathrm{GPa}$, linear-elastic up to a first yield stress of $\sigma_{y}=250 \mathrm{MPa}$, followed by $2.5 \%$ linear strain hardening up to an ultimate stress of $\sigma_{u}=380 \mathrm{MPa}$. For simplicity, after the ultimate stress $\sigma_{u}$ was reached, an indefinitely ductile plateau was assumed and no rupture or cracking was implemented in the material model. ABAQUS [17] v.6.10.1 was used and the nonlinear equilibrium path was followed using the Riks modified arc-length method [53]. This particular choice of software package was made due to its widespread use and credibility in previous research work in this field and due to its arguably very extensive element library, though the results may readily be generalised to other commercial and academic finite element packages. 
Published in: International Journal of Mechanical Sciences, 74, 143-153.

DOI: http://dx.doi.org/10.1016/j.ijmecsci.2013.05.008

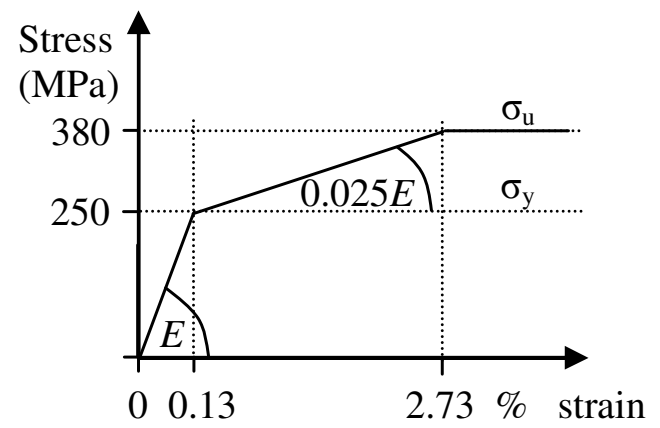

Fig. 2 - Assumed engineering stress-strain relation, with 2.5\% linear strain hardening

The bending moment was applied through a reference point at the centre of the crosssection at both ends as shown in Fig. 3, drawn using the right-hand screw convention. The moment was transferred into the end nodes of the tube through a rigid body kinematic coupling. The end notes were not permitted to displace in the plane of the ends of the undeformed tube or to rotate into the plane of circumferential symmetry, keeping the end section circular, but free to displace axially. The reference applied moment was the full plastic moment $M_{p}$ (small displacement theory) assuming an ideal elastic-plastic material, and is given by:

$M_{p}=\frac{4}{3} \sigma_{y}\left[\left(R+\frac{t}{2}\right)^{3}-\left(R-\frac{t}{2}\right)^{3}\right]$

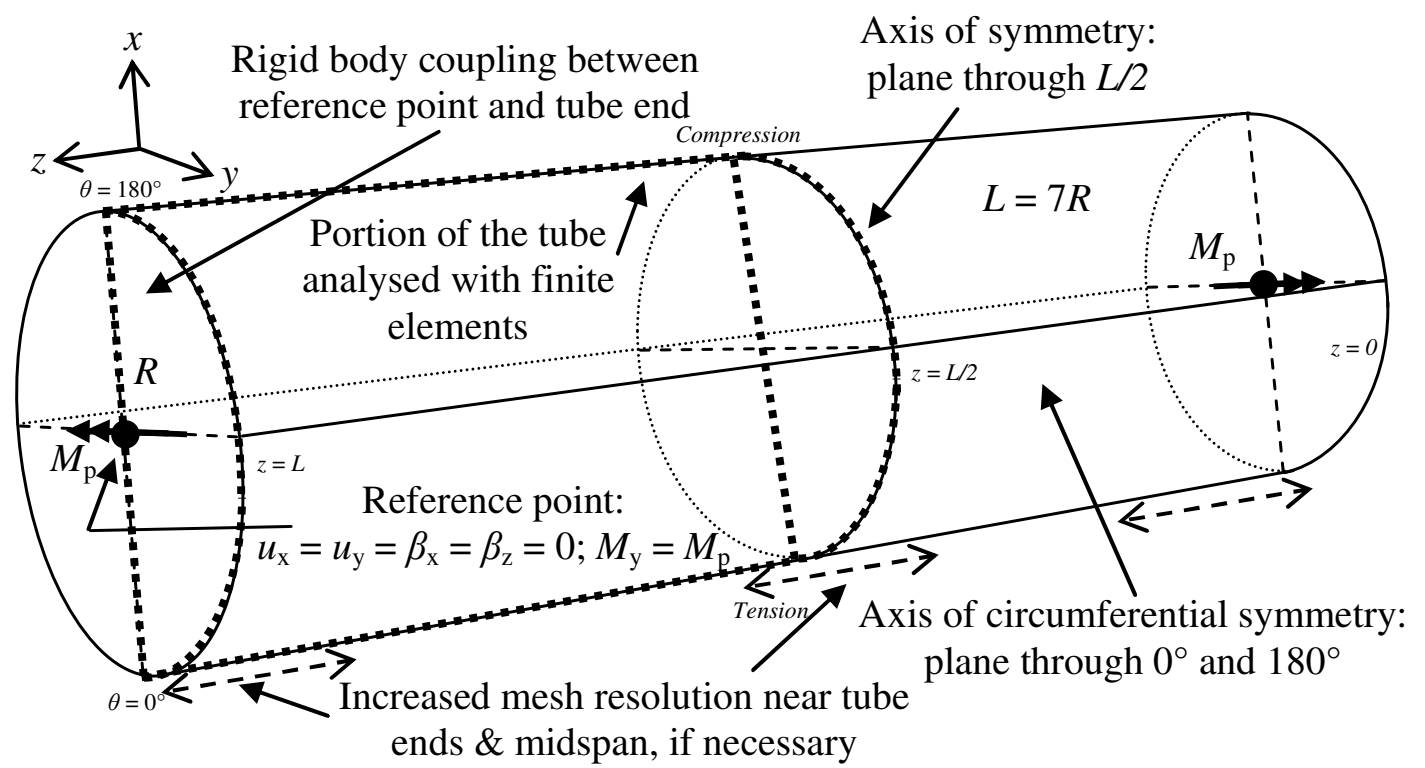

Fig. 3 - Features of the numerical model for both shell and solid elements 
Published in: International Journal of Mechanical Sciences, 74, 143-153.

DOI: http://dx.doi.org/10.1016/j.ijmecsci.2013.05.008

The tube geometry was initially assumed to be perfect with no modelled imperfections. Symmetry conditions were exploited where possible for a more efficient analysis (Fig. 3 ), consistent with previous numerical research [46,47,50,51]. Because the calculations were performed on a powerful computer, it was not considered necessary to economise on the mesh and some analyses employed many more dofs than was strictly necessary. Local shell bending effects were observed near the ends $(z=0, L)$ in tubes with $R / t=25$ and 50 as well as local bifurcation buckling at midspan $(z=L / 2)$, so the mesh resolution was increased at these locations to keep the element size well below $0.25 \sqrt{R t}$ (i.e. approximately $10 \%$ of the linear axial bending half-wavelength $\lambda$ $\approx 2.44 \sqrt{R t}$ or $14 \%$ of the classical axisymmetric buckle wavelength $\lambda_{c l} \approx 1.73 \sqrt{R t}$ $[54,55])$. This mesh resolution was verified by a careful initial mesh convergence study.

The extensive ABAQUS [17] element library contains many elements corresponding closely to generic solid continuum and thick and thin shell finite element formulations. It is unfeasible and unnecessary to test all possible elements for this specific problem, so a representative selection was made of three element types from each of the theoretical treatments. Tetrahedral and triangular elements are known to be sometimes unreliable and overly stiff $[17,56,57]$ for problems involving extensive bending or high strain gradients, unless used with an extremely fine mesh, so only hexahedral and rectangular elements were used. The chosen solid and shell elements are summarised in Tables 1 and 2 respectively. 
Published in: International Journal of Mechanical Sciences, 74, 143-153.

DOI: http://dx.doi.org/10.1016/j.ijmecsci.2013.05.008

Table 1 - Selected 3D solid continuum finite element formulations with ABAQUS implementations

\begin{tabular}{|c|c|c|c|c|}
\hline Name & Order & Type & $\begin{array}{c}\text { No. of integration } \\
\text { points }\end{array}$ & Other \\
\hline $\begin{array}{c}\text { Brick-8 } \\
(\mathrm{C} 3 \mathrm{D} 8 \mathrm{R})\end{array}$ & $\begin{array}{c}1 \mathrm{st} \\
\text { (linear) }\end{array}$ & $\begin{array}{c}8 \text {-noded } \\
\text { brick }\end{array}$ & $1 \times 1 \times 1$ & $\begin{array}{c}\text { Reduced integration, 3 } \\
\text { displacement dofs/node }\end{array}$ \\
\hline Brick-8I & 1 st & 8 -noded & $2 \times 2 \times 2$ & 3 displacement +13 \\
(C3D8I) & (linear) & brick & & incompatible modes dofs \\
\hline Brick-20 & 2nd & $\begin{array}{c}20 \text {-noded } \\
\text { brick }\end{array}$ & $2 \times 2 \times 2$ & $\begin{array}{c}\text { Reduced integration, 3 } \\
\text { displacement dofs/node }\end{array}$ \\
\hline
\end{tabular}

The first-order reduced-integration Brick-8 solid continuum element is a constantstrain element with a single Gauss integration point and is reported [17] to produce inferior results under certain load conditions, unless extremely fine meshes are used. The first-order Brick-8I element is fully-integrated with $2 \times 2 \times 2$ internal Gauss points, includes 13 additional 'internal dofs per element for incompatible modes [58,59] and is of comparable accuracy to the higher-order Brick-20. The reduced integration 20noded brick element has the same number of through-thickness Gauss integration points as Brick-8I $(2 \times 2 \times 2)$ but yields [17] more accurate results in stress analyses than the corresponding fully-integrated 20 -noded brick element which boasts $3 \times 3 \times 3$ integration points and is an order of magnitude more computationally expensive. The issue of parasitic shears leading to an overly stiff response in bending in the plane of a first-order solid continuum element is thought to be of minor significance here as only reduced-integration or incompatible mode solid continuum elements were used. The formulation of each of these solid elements allows for large strains and rotations, and employs the flow theory of plasticity though the use of kinematic plastic strain hardening is not recommended for strains greater than 20-30\% [60]. Such levels of strain were not reached in the analyses performed for this study. 
Published in: International Journal of Mechanical Sciences, 74, 143-153.

DOI: http://dx.doi.org/10.1016/j.ijmecsci.2013.05.008

Table 2 - Selected 3D structural shell finite element formulations with ABAQUS implementation

\begin{tabular}{|c|c|c|c|c|}
\hline Name & Order & Type & Shell theory & Other \\
\hline $\begin{array}{l}\text { Thick- } \\
\text { shell-4 } \\
\text { (S4R) }\end{array}$ & $\begin{array}{c}\text { 1st } \\
\text { (linear) }\end{array}$ & $\begin{array}{c}\text { 4-noded } \\
\text { doubly-curved } \\
\text { rectangle }\end{array}$ & $\begin{array}{c}\text { Thick \& thin } \\
\text { depending } \\
\text { on thickness }\end{array}$ & $\begin{array}{c}\text { Finite strain, reduced integration, } \\
\text { hourglass control, } 6 \text { dofs/node }\end{array}$ \\
\hline $\begin{array}{l}\text { Thick- } \\
\text { shell-8 } \\
\text { (S8R) }\end{array}$ & $\begin{array}{c}\text { 2nd } \\
\text { (quadratic) }\end{array}$ & $\begin{array}{c}\text { 8-noded } \\
\text { doubly-curved } \\
\text { rectangle }\end{array}$ & Thick & $\begin{array}{l}\text { Small strain, finite rotation, } \\
\text { reduced integration, } 6 \text { dofs/node }\end{array}$ \\
\hline $\begin{array}{l}\text { Thin- } \\
\text { shell-9 } \\
\text { (S9R5) }\end{array}$ & $\begin{array}{c}\text { 2nd } \\
\text { (quadratic) }\end{array}$ & $\begin{array}{c}\text { 9-noded } \\
\text { doubly-curved } \\
\text { rectangle }\end{array}$ & Thin & $\begin{array}{l}\text { Small strain, finite rotation, } \\
\text { reduced integration, } 5 \text { dofs/node }\end{array}$ \\
\hline
\end{tabular}

Each of the shell elements investigated in this study employs reduced integration, which permits extensive savings in computation time. Additionally, such elements are known to be generally free of shear locking [17,61,62,63]. The first-order Thick-shell4 element is as a general-purpose shell element with 6 dofs per node ( 3 displacements and 3 rotations), applicable for most thick and thin shell applications and permitting large strains. Its present formulation includes a stabilisation parameter that effectively eliminates artificial 'hourglass' deformation modes. It employs thick (Mindlin) shell theory when necessary and becomes a 'discrete Kirchhoff' element for thin shells. The second-order Thick-shell-8 element is similar and includes finite rotations, though its formulation only permits small strains is suitable only for thick shell analyses. The second-order Thin-shell-9 element formulation assumes only 5 dofs per node (3 displacements and 2 tangential rotations) and includes an additional centre node, apparently for improved numerical stability [17,64,65]. It is recommended for use in elastic thin-shell buckling problems and it has been described as a robust and efficient element in a variety of structural engineering problems (e.g. [63,66,67,68]). Lastly, though all solid elements are naturally capable of modelling changes in wall thickness due to Poisson effects, the only shell element that can do so is the Thick-shell-4 element due to its finite strain formulation. The strain measures in each of these shell elements are approximations to those of the Koiter-Sanders shell theory [69]. Other 
Published in: International Journal of Mechanical Sciences, 74, 143-153.

DOI: http://dx.doi.org/10.1016/j.ijmecsci.2013.05.008

finite strain formulations for shear-flexible shell finite elements include those of Bathe et al. [70], Ramm et al. [71], Bischoff and Ramm [72] and many others.

The analysis of thick shells or thin tubes subject to global bending is a relatively 'smooth' nonlinear problem with no contact conditions, sharp stress localisations or severe element distortions [1,17]. A second-order Brick-20 element might therefore be thought to offer the 'best' solution of all the elements explored. It remains, however, difficult to say with full certainty a priori which element should give the 'right' answer for any particular $R / t$ ratio, even for this apparently simple benchmark test. It may also be noted that experiments on cylinders of this kind tend to display some scatter between individual apparently identical tests, and the mismatches with computational predictions are generally comparable in magnitude to the differences between the predictions of different elements in this study. Consequently no attempt is made here to select the "correct" result on the basis of a match with physical testing.

\section{Results of the nonlinear buckling analyses}

\subsection{Bending of cylindrical tubes with $R / t=10$}

The preceding selection of shell and solid continuum elements were used to predict the behaviour of the thick cylindrical tube with $R / t=10$. The peak moments predicted by each formulation and selected properties of the meshes are summarised in Table 3. The predicted relationships between applied moment and the normalised mean tube curvature are presented in Fig. 4, with a close-up view near the limit point in Fig. 5. This normalised curvature $\Phi$ is defined as the ratio of the end rotation $\beta_{y}$ about the $y$ axis (Fig. 3) to its first yield value given by $L \sigma_{y} /(E R)$ for a cross-section that is free of ovalisation. A normalised curvature value of unity is thus reached at the point of first yield in a section that does not distort. 
Published in: International Journal of Mechanical Sciences, 74, 143-153.

DOI: http://dx.doi.org/10.1016/j.ijmecsci.2013.05.008

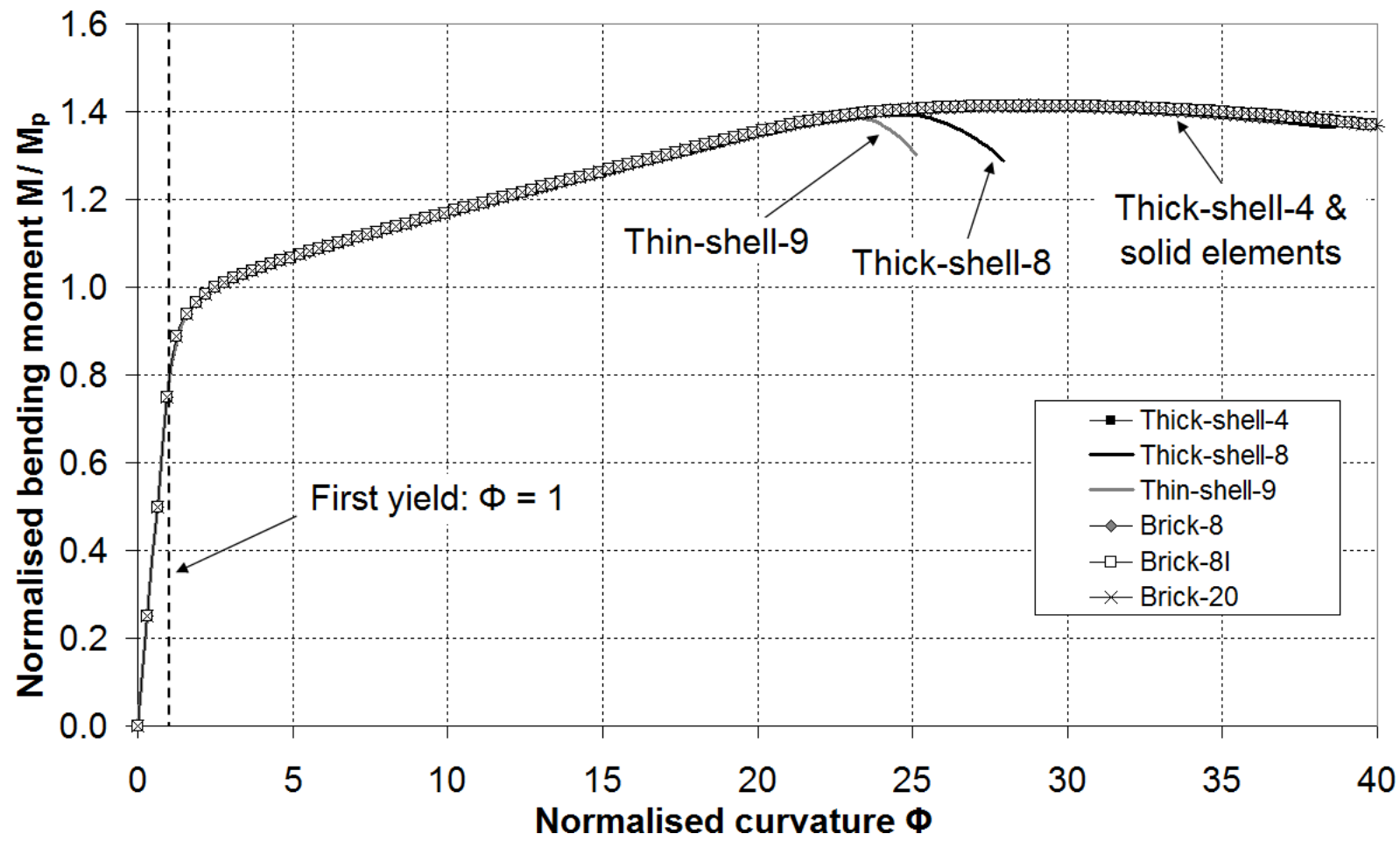

Fig. 4 - Normalised moment-curvature curves for $R / t=10$

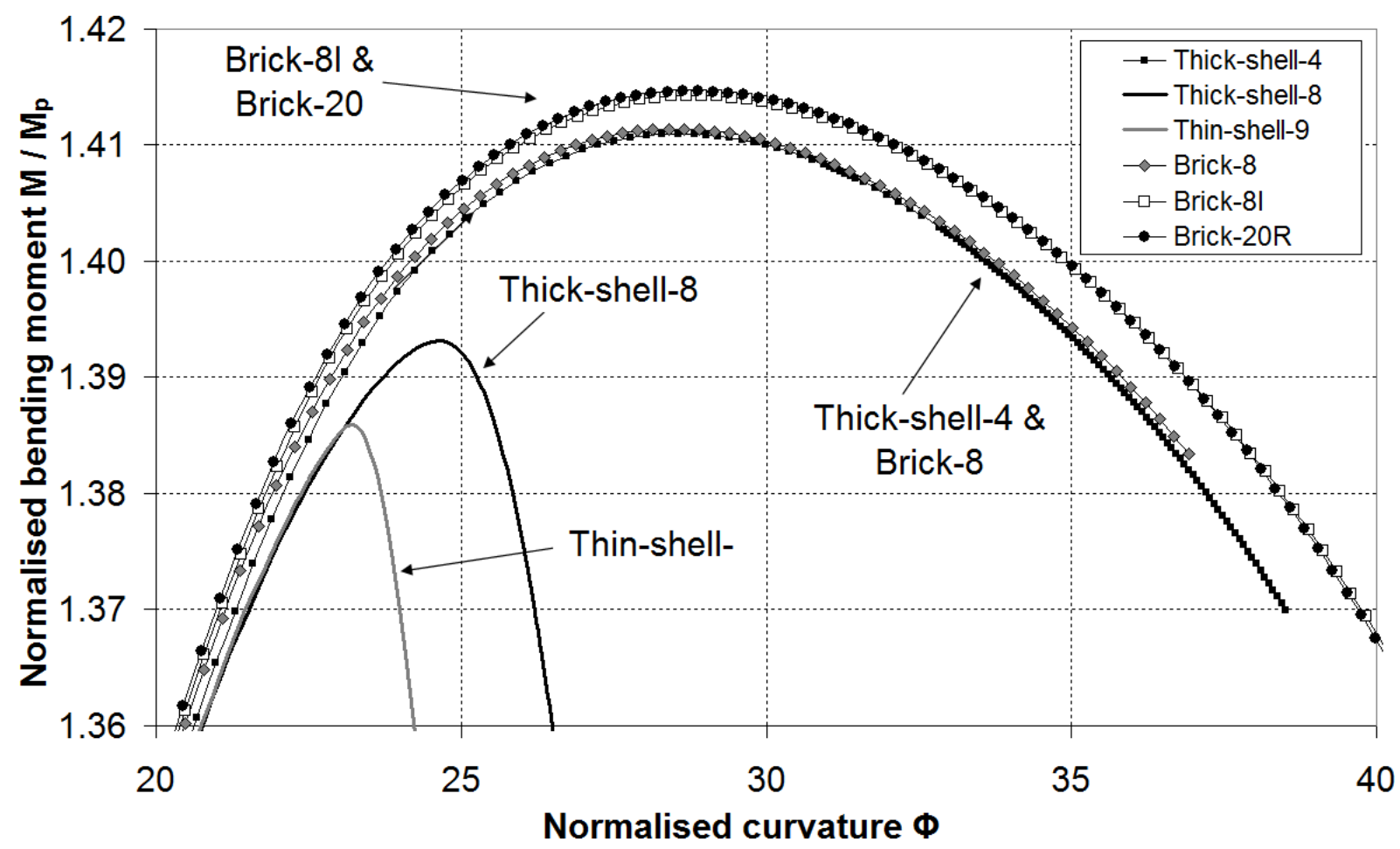

Fig. 5 - Normalised moment-curvature curves for $R / t=10$ : close-up near limit point

The analyses that employed a solid continuum treatment were all successful in following the primary load path well into the post-buckling range and predicted a limit moment at approximately $1.41 M_{\mathrm{p}}$. This thick cylinder reaches a limit point snap- 
Published in: International Journal of Mechanical Sciences, 74, 143-153.

DOI: http://dx.doi.org/10.1016/j.ijmecsci.2013.05.008

through buckle (Fig. 6) due to extensive plasticity and cross-section ovalisation. The possible secondary path, involving axial wrinkling, is not found even very far into the post-buckling range. The Brick-8I and Brick-20 solid continuum elements predict nearly identical responses (Fig. 4 \& 5), which are slightly stiffer and consequently stronger (by $0.3 \%$ ) than the predictions of the Brick- 8 and Thick-shell- 4 elements. The very small differences between these three analyses are so tiny as to make them effectively all the same in engineering terms, so the results from these three elements are here deemed to be the 'correct' numerical prediction.

The corresponding analyses employing a shell treatment were problematic. The Riks algorithm was able to follow the primary equilibrium path until the limit point was almost reached, but encountered severe numerical difficulties when attempting to go into the post-buckling range. A solution was finally obtained by increasing the number of section integration points from 5 (default) to at least 5 times that number (Simpson's rule) together with a small mesh perturbation. This perturbation was axially sinusoidal but in the ovalising circumferential harmonic two $\left(\delta=\delta_{0} \sin (\pi z / L) \cos (2 \theta)\right)$ with an amplitude $\delta_{\mathrm{O}} \approx 10^{-2} t$, where $\theta$ is the circumferential coordinate (Fig. 3). This form maintained the ends circular and reflected the shape of the global nonlinear collapse mode (Fig. 6).

Using this slightly perturbed mesh, the Thick-shell-4 element reproduced the same path as the Brick-8 element, with an identical limit moment and post-buckling response, but using far fewer dofs. This success is attributable to its finite strain formulation, which allows the Thick-shell-4 element to model changes in wall thickness, albeit not quite as well as the solid continuum elements (Table 3). The Thick-shell-8 and Thin-shell-9 elements both predicted a limit moment within $2 \%$ of the 'correct' value. However, the predicted post-buckling response was not good, as the moment dropped to $95 \%$ of the limit value at a rotation only slightly greater than half the correct value. This appears to be caused by the small strain formulation which renders these elements unable to model changes in wall thickness. 
Published in: International Journal of Mechanical Sciences, 74, 143-153.

DOI: http://dx.doi.org/10.1016/j.ijmecsci.2013.05.008

\section{Solid continuum elements}

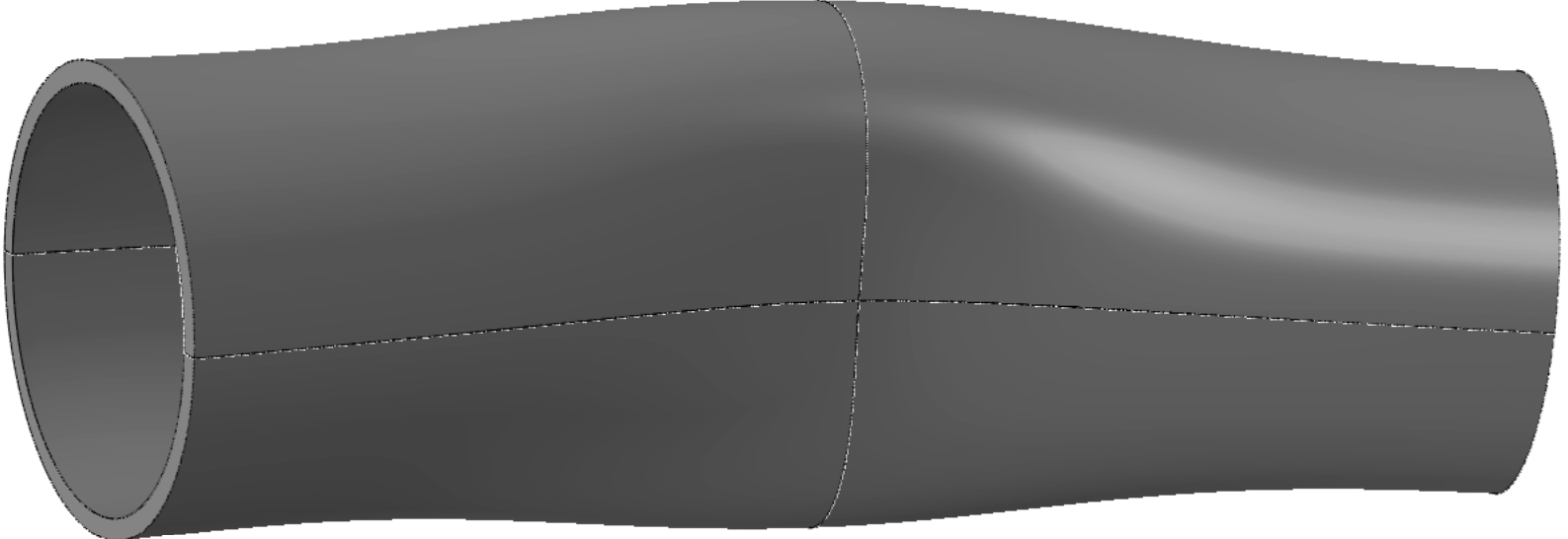

Shell elements

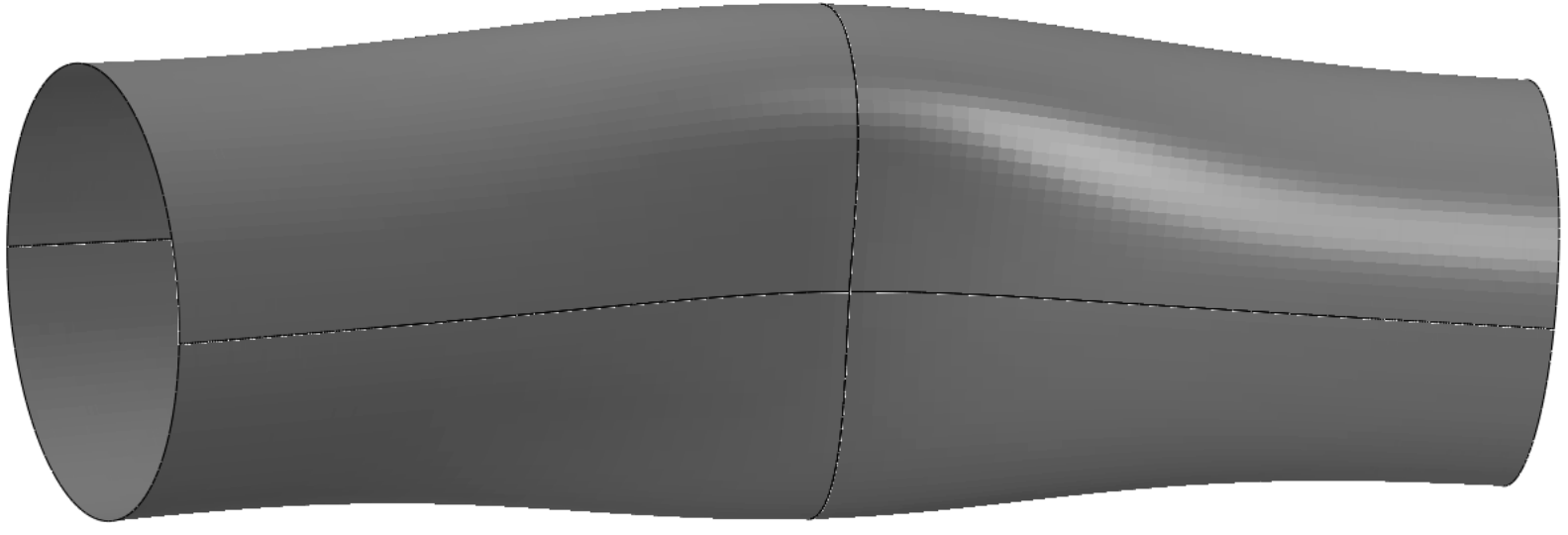

Fig. 6 - Predicted buckling modes for $R / t=10$

Table 3 - Buckling moments and selected mesh properties for $R / t=10$

\begin{tabular}{|c|c|c|c|c|c|c|}
\hline$R / t=10$ & Brick-8 & Brick-8I & Brick-20 & $\begin{array}{c}\text { Thick- } \\
\text { shell-4 }\end{array}$ & $\begin{array}{c}\text { Thick- } \\
\text { shell-8 }\end{array}$ & $\begin{array}{c}\text { Thin- } \\
\text { shell-9 }\end{array}$ \\
\hline $\begin{array}{c}\text { No. of elements } \\
\text { through wall thickness }\end{array}$ & 4 & 4 & 2 & $\mathrm{n} / \mathrm{a}$ & $\mathrm{n} / \mathrm{a}$ & $\mathrm{n} / \mathrm{a}$ \\
\hline $\begin{array}{c}\text { Axial element size } \\
\text { Total no. of dofs }\end{array}$ & $0.08 \sqrt{ }(R t)$ & $0.08 \sqrt{ }(R t)$ & $0.17 \sqrt{ }(R t)$ & $0.04 \sqrt{ }(\mathrm{Rt})$ & $0.09 \sqrt{ }(R t)$ & $0.08 \sqrt{ }(R t)$ \\
\hline $\begin{array}{c}\text { \% change in thickness } \dagger \\
\text { (compressive side) }\end{array}$ & +2.45 & +2.46 & +2.47 & +1.10 & $\mathrm{n} / \mathrm{a}$ & $\mathrm{n} / \mathrm{a}$ \\
\hline $\begin{array}{c}\% \text { change in thickness } \dagger \\
\text { (tensile side) }\end{array}$ & -1.65 & -1.68 & -1.68 & -0.75 & $\mathrm{n} / \mathrm{a}$ & $\mathrm{n} / \mathrm{a}$ \\
\hline $\begin{array}{c}\text { Buckling moment } \\
M_{\mathrm{GMNA}} / M_{\mathrm{pl}}\end{array}$ & $\mathbf{1 . 4 1 1}$ & $\mathbf{1 . 4 1 4}$ & $\mathbf{1 . 4 1 5}$ & $\mathbf{1 . 4 1 1}$ & $\mathbf{1 . 3 9 3}$ & $\mathbf{1 . 3 8 6}$ \\
\hline
\end{tabular}

$\dagger$ at the buckling moment 
Published in: International Journal of Mechanical Sciences, 74, 143-153.

DOI: http://dx.doi.org/10.1016/j.ijmecsci.2013.05.008

Plasticity clearly dominates the failure mode of such thick cylinders under bending. For an ideal elastic-plastic material without cross-section distortion, the entire crosssection must be fully yielded to attain the full plastic moment $M_{p}$. But in the presence of strain hardening, $M_{p}$ is reached and significantly exceeded before bifurcation or a limit point. It should be recalled that some manner of hardening, be it geometric or strain-related, is essential for the full plastic moment to be reached in a numerical analysis, and since cylinders under global bending do not exhibit any geometric hardening (ovalisation is destabilising), even at massive rotations of the tube ends, $M_{p}$ cannot be reached without strain hardening (e.g. $[73,74])$.

The degree of ovalisation is illustrated in Fig. 7 in terms of the convenient out-ofroundness parameter $U$ used in the European Standard on shell buckling EN 1993-1-6 [52], defined as $U=\left(D_{\max }-D_{\min }\right) / D_{\text {nom }}$ where $D_{\text {nom }}, D_{\min }$ and $D_{\max }$ are the nominal, minimum and maximum diameters respectively at any step in the analysis. To provide a comparison, typical ovalisation fabrication tolerances are of the order of $U \approx 0.01$, whereas for $R / t=10$ this study found an ovalisation of $U \approx 0.08$ at the maximum moment. Ovalisation of the cross-section is thus significant in medium-length tubes even when they are very thick, though the peak moment is of course far below the elastic Brazier snap-through moment $M_{B r a z} \approx 1.035 E t^{2} R$ because of the dominant effect of plasticity $\left(M_{B r a z} / M_{p} \approx 20.7,8.3\right.$ and 4.1 for $R / t=10,25$ and 50 respectively).

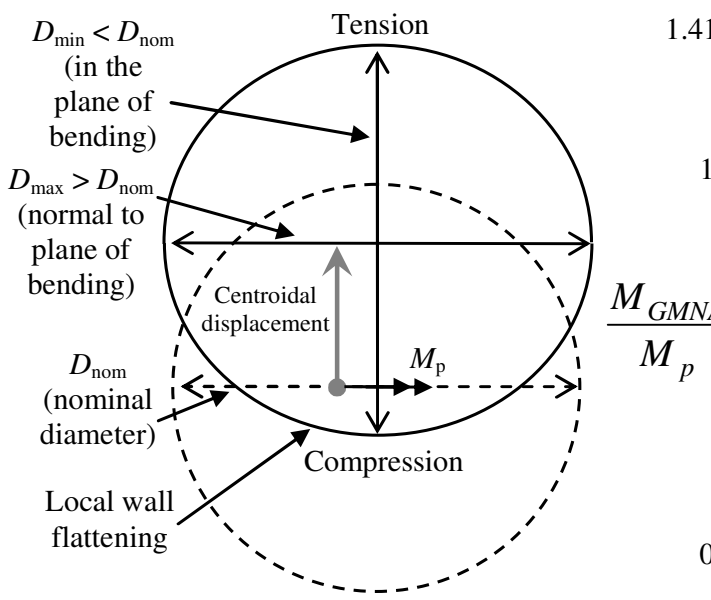

Fig. 7 - Illustration of the effect of ovalisation for $R / t=10$ 
Published in: International Journal of Mechanical Sciences, 74, 143-153.

DOI: http://dx.doi.org/10.1016/j.ijmecsci.2013.05.008

\subsection{Bending of cylindrical tubes with $R / t=25$}

For the cylindrical tube with $R / t=25$, the predicted moment-curvature paths are presented in Figs 8 and 9. The buckling moments and mesh details are summarised in Table 4. In a manner similar to $R / t=10$, the tube undergoes significant strain hardening and ovalisation leading to a limit point at approximately $1.28 M_{p}$. However, a bifurcation onto a secondary equilibrium path is encountered close to the peak moment and in the post-buckling condition, local axial wrinkling occurs with a halfwavelength of approximately $1.8 \sqrt{ }(R t)$ (Fig. 9) which is very comparable with the halfwavelength for axisymmetric buckles under uniform compression [54,55]. This wavelength was always modelled with more than 10 solid or 40 shell element lengths. No perturbation of the shell element meshes was necessary for these analyses and no numerical difficulties were encountered.

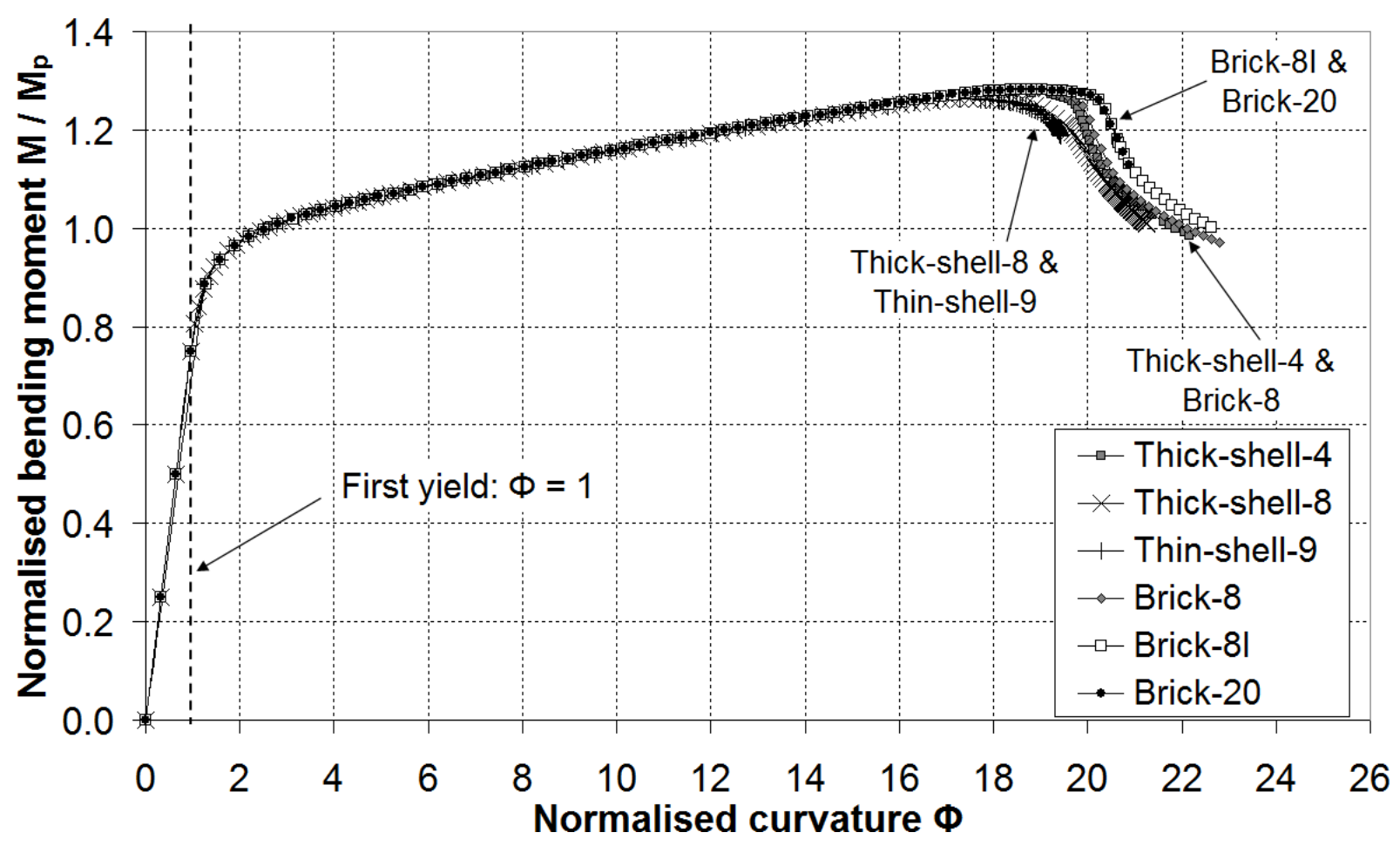

Fig. 8 - Normalised moment-curvature curves for $R / t=25$

However, the rather rounded transition from the pre-buckling to the post-bifurcation paths, seen in the detailed examination of these curves (Fig. 9), deserves explanation. Such behaviour is typical of shells with very small imperfections [75]. No intentional imperfections were used in these models, but it may be noted that all of these elements are not truly circular in their geometry and that small round-off errors in the plasticity 
Published in: International Journal of Mechanical Sciences, 74, 143-153.

DOI: http://dx.doi.org/10.1016/j.ijmecsci.2013.05.008

modelling may also cause some tiny imperfections. Indeed, even second-order elements offer at best a quadratic local approximation to what should be an exactly circular geometry for the tube. Thus if the 'true' bifurcation is estimated as the intersection of the extrapolated pre-buckling and post-buckling paths, the drop in the predicted peak moment is less than $1 \%$. Elastic imperfection sensitivity curves for this load case in thin shells $[32,76]$ indicate that such a fall could reasonably be caused by an imperfection of amplitude in the order of $\delta_{o}=0.001 t-0.01 t$, which is clearly possible here despite the very fine mesh.

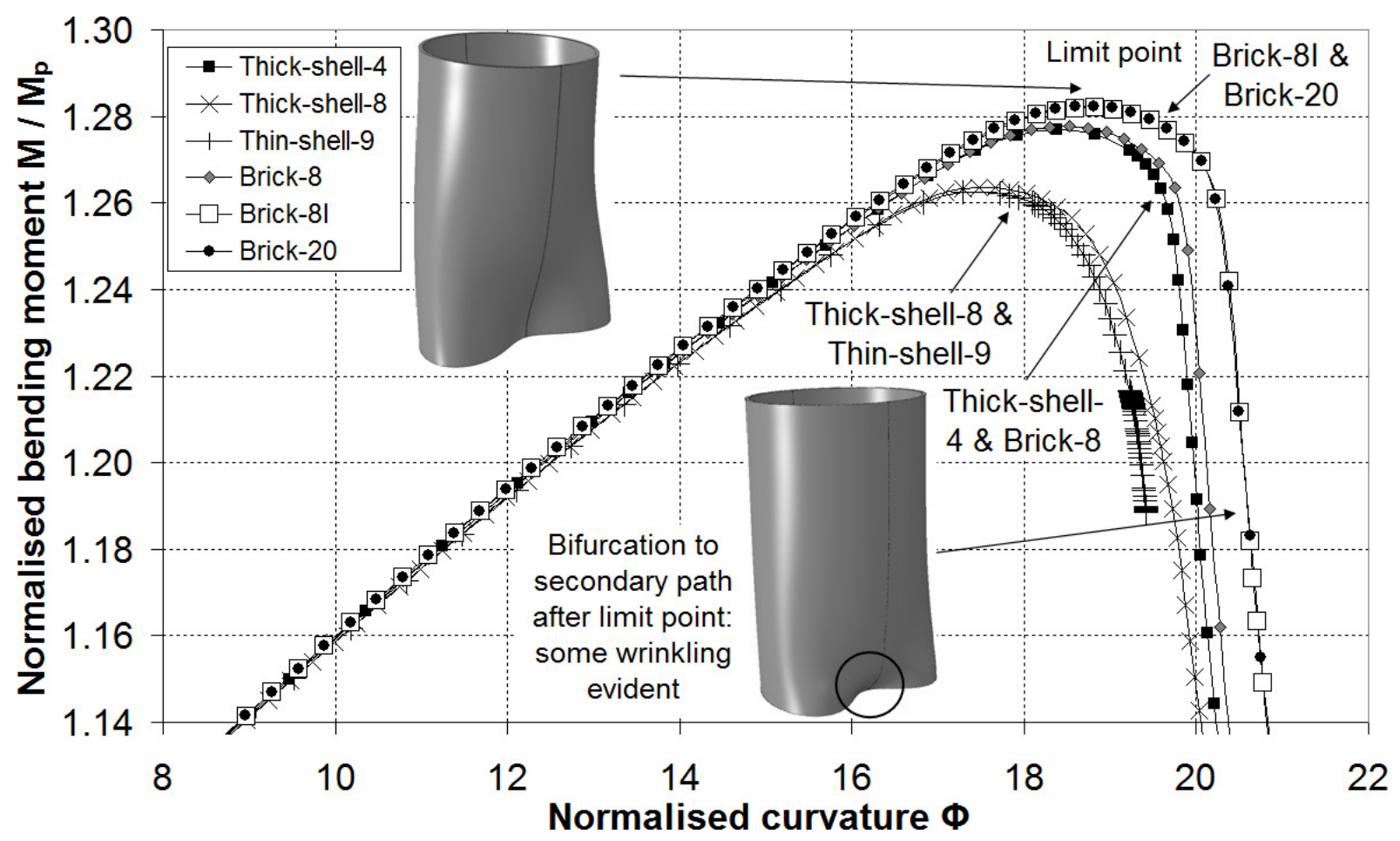

Fig. 9 - Normalised moment-curvature curves for $R / t=25$ : close up near limit point

In general, the close-up view of the peak of these curves (Fig. 9) suggests that similar conclusions concerning the elements may be drawn for $R / t=25$ as for $R / t=10$. The Brick-8I and Brick-20 solid continuum elements appear to follow identical paths and give a marginally higher prediction of the peak moment. The first order Brick-8 element is close on their heels, with the finite strain Thick-shell-4 element also very close behind predicting a peak moment that is lower by $0.3 \%$. The Thick-shell- 8 Thinshell-9 elements both predict a slightly lower moment at the limit point and transition from prebuckling to post-buckling with more equivalent imperfection. 
Published in: International Journal of Mechanical Sciences, 74, 143-153.

DOI: http://dx.doi.org/10.1016/j.ijmecsci.2013.05.008

Nevertheless, the buckling moments are all within $1 \%$ of each other and no experiments are known that can achieve the accuracy necessary to identify a 'correct' result between different numerical models. Both the solid and shell treatments predict the same buckling mode (Fig. 10). As the cylinder becomes thinner, it becomes increasingly uneconomical to use solid elements because at least two layers are required to model the through-thickness stress distribution properly (four layers for the reduced-integration first-order Brick- 8 element with a single Gauss integration point per element - Table 1). This greatly increases the required degrees of freedom. Additionally, solid elements no longer offer any useful increase in accuracy over the much cheaper finite strain Thick-shell-4 element. Nevertheless, the differences between the predictions of all six elements are relatively small, so all may be regarded as providing an adequate modelling at this radius to thickness ratio.

\section{Solid continuum elements}

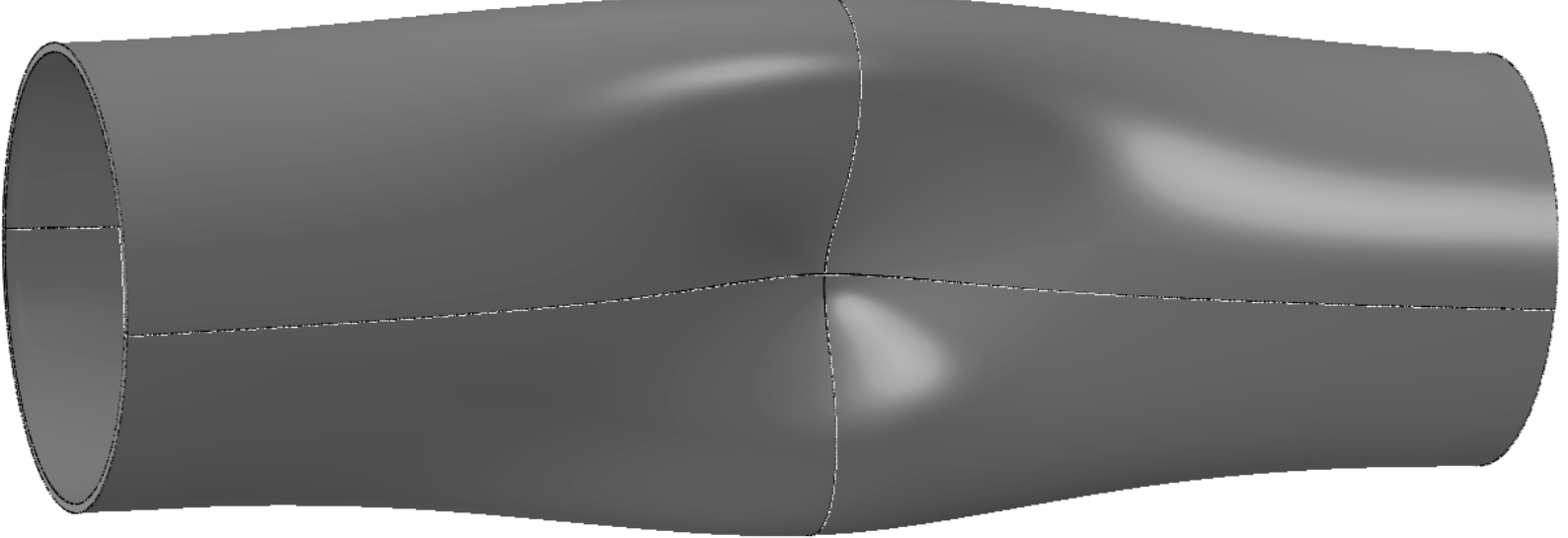

Shell elements

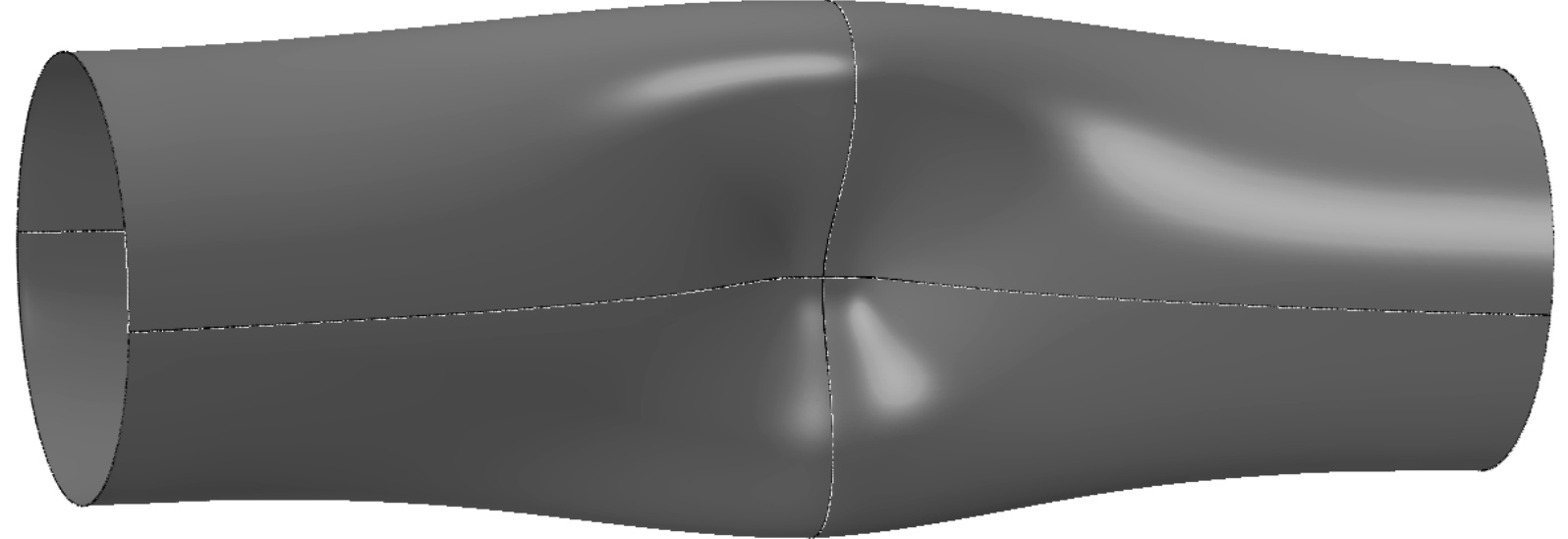

Fig. $10-$ Predicted buckling modes for $R / t=25$ 
Published in: International Journal of Mechanical Sciences, 74, 143-153.

DOI: http://dx.doi.org/10.1016/j.ijmecsci.2013.05.008

Lastly, the present formulation of thick and thin second-order shell elements only permits small strains. The circumferential distribution of the axial plastic membrane strains at the limit point through the axis of longitudinal symmetry at midspan $(1 / 2 L)$ is shown in Fig. 11. This part of the cylinder experienced the highest stresses and strains, yet the maximum membrane plastic strains at buckling were only of the order of $3.5 \%$. Elastic strains were naturally smaller, of the order of $0.2 \%$. As no post-bifurcation deformations have yet developed, there is no axial wrinkling of the shell with its associated high local curvatures, so the surface strains are very similar to the membrane strains. These strain magnitudes are clearly small enough to allow a smallstrain shell element to follow the path at least as far as the limit point. However, it is best if a shell element can model local changes in wall thickness to obtain an accurate prediction of the post-buckling ductility in shells with low $R / t$. Neither of the small strain second-order shell elements is able to do this. The apparently cruder first-order Thick-shell-4 element clearly offers the most accurate shell element treatment in this case (Fig. 9).

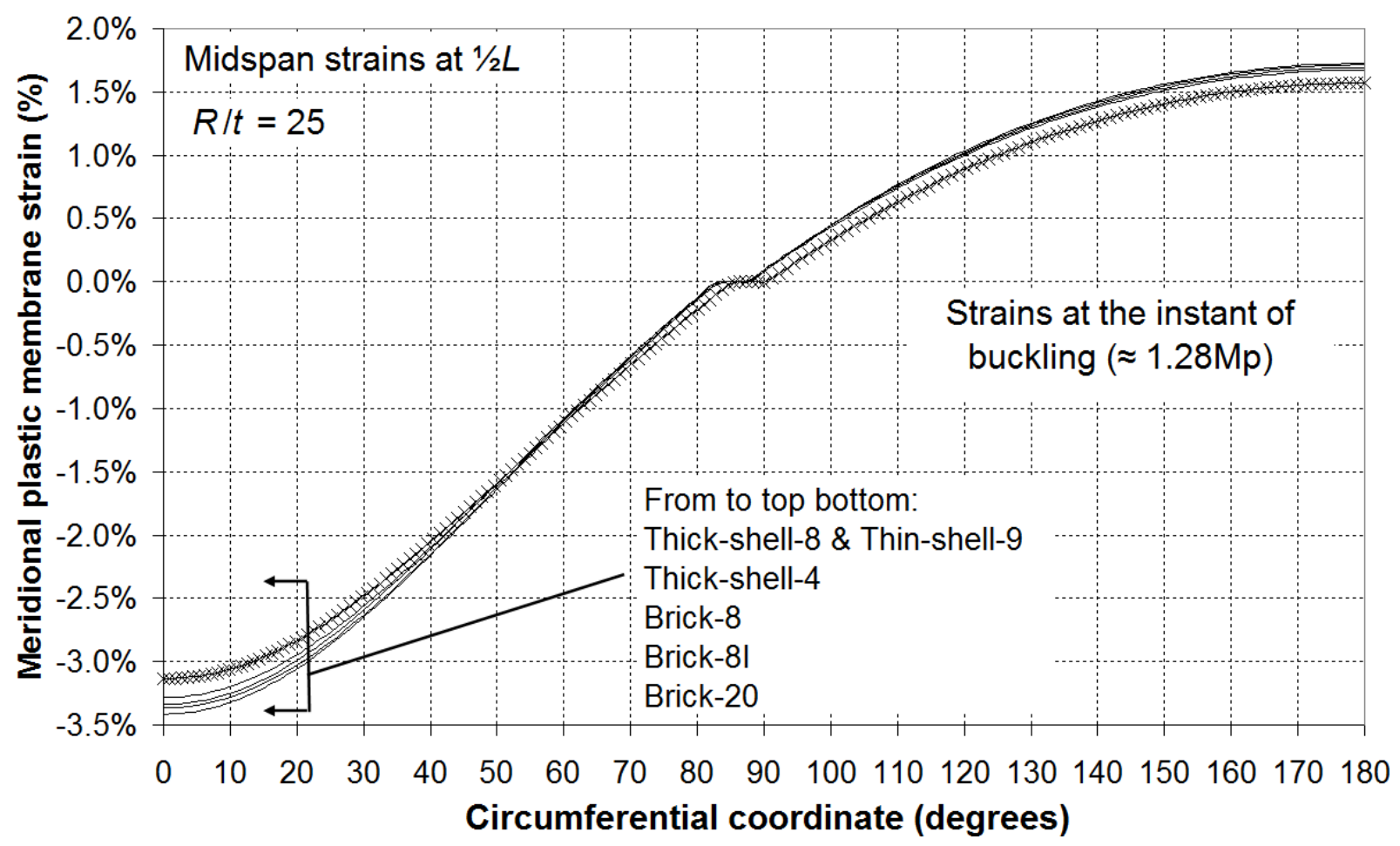

Fig. 11 - Axial plastic membrane strains at the instant of buckling through the axis of axial symmetry $(1 / 2 L-$ midspan $)$ 
Published in: International Journal of Mechanical Sciences, 74, 143-153.

DOI: http://dx.doi.org/10.1016/j.ijmecsci.2013.05.008

Table 4 - Buckling moments and selected mesh properties for $R / t=25$

\begin{tabular}{|c|c|c|c|c|c|c|}
\hline$R / t=25$ & Brick-8 & Brick-8I & Brick-20 & $\begin{array}{c}\text { Thick- } \\
\text { shell-4 }\end{array}$ & $\begin{array}{c}\text { Thick- } \\
\text { shell-8 }\end{array}$ & $\begin{array}{c}\text { Thin- } \\
\text { shell-9 }\end{array}$ \\
\hline $\begin{array}{c}\text { No. of elements } \\
\text { through wall thickness }\end{array}$ & 4 & 4 & 2 & n/a & $\mathrm{n} / \mathrm{a}$ & $\mathrm{n} / \mathrm{a}$ \\
\hline $\begin{array}{c}\text { Min. axial } \\
\text { element size }\end{array}$ & $0.10 \sqrt{ }(R t)$ & $0.10 \sqrt{ }(R t)$ & $0.13 \sqrt{ }(R t)$ & $0.03 \sqrt{ }(R t)$ & $0.04 \sqrt{ }(R t)$ & $0.04 \sqrt{ }(R t)$ \\
\hline $\begin{array}{c}\text { Max. axial } \\
\text { element size }\end{array}$ & $0.10 \sqrt{ }(R t)$ & $0.10 \sqrt{ }(R t)$ & $0.13 \sqrt{ }(R t)$ & $0.23 \sqrt{ }(R t)$ & $0.28 \sqrt{ }(R t)$ & $0.28 \sqrt{ }(R t)$ \\
\hline $\begin{array}{c}\text { Total no. of dofs } \\
\text { (compressive side) }\end{array}$ & 419,496 & $1,848,196$ & 531,231 & 174,852 & 196,932 & 261,732 \\
\hline $\begin{array}{c}\% \text { change in thickness } \dagger \\
\text { (tensile side) }\end{array}$ & -0.87 & -0.89 & -0.89 & -0.40 & $\mathrm{n} / \mathrm{a}$ & $\mathrm{n} / \mathrm{a}$ \\
\hline $\begin{array}{c}\text { Buckling moment } \\
M_{\mathrm{GMNA}} / M_{\mathrm{pl}}\end{array}$ & $\mathbf{1 . 2 7 8}$ & $\mathbf{1 . 2 8 2}$ & $\mathbf{1 . 2 8 2}$ & $\mathbf{1 . 2 7 9}$ & $\mathbf{1 . 2 6 2}$ & $\mathbf{1 . 2 6 2}$ \\
\hline
\end{tabular}

$\dagger$ at the buckling moment

\subsection{Bending of cylindrical tubes with $R / t=50$}

For the cylindrical tube with $R / t=50$, the predicted equilibrium paths and buckling modes are presented in Figs 12, 13 and 14. The mesh details and buckling moments are summarised in Table 5. As the tube is now relatively thin, the primary ovalisation path bifurcates onto the secondary wrinkling path well before the limit point and the cylinder experiences a sudden elastic-plastic bifurcation. The axial half-wavelength of the local wrinkling mode is approximately $3.5 \sqrt{ }(R t)$, corresponding to at least 20 element lengths. These wrinkles are roughly twice as long as those in the thicker tube and are quickly followed by localisation. The simple Brick-8 solid continuum element now becomes very uneconomical indeed, since four layers of these elements (with only 4 integration points through the thickness) are needed to obtain an acceptable approximation of the rapidly-varying axial bending near the ends of the tube. A better outcome was achieved using only 2 layers of Brick-8I or Brick-20 elements due to the larger number of integration points (Table 1). However, the number of required dofs 
Published in: International Journal of Mechanical Sciences, 74, 143-153.

DOI: http://dx.doi.org/10.1016/j.ijmecsci.2013.05.008

in all solid element cases is almost three times that of the simplest shell elements, with no noticeable advantage in the accuracy of the solution.

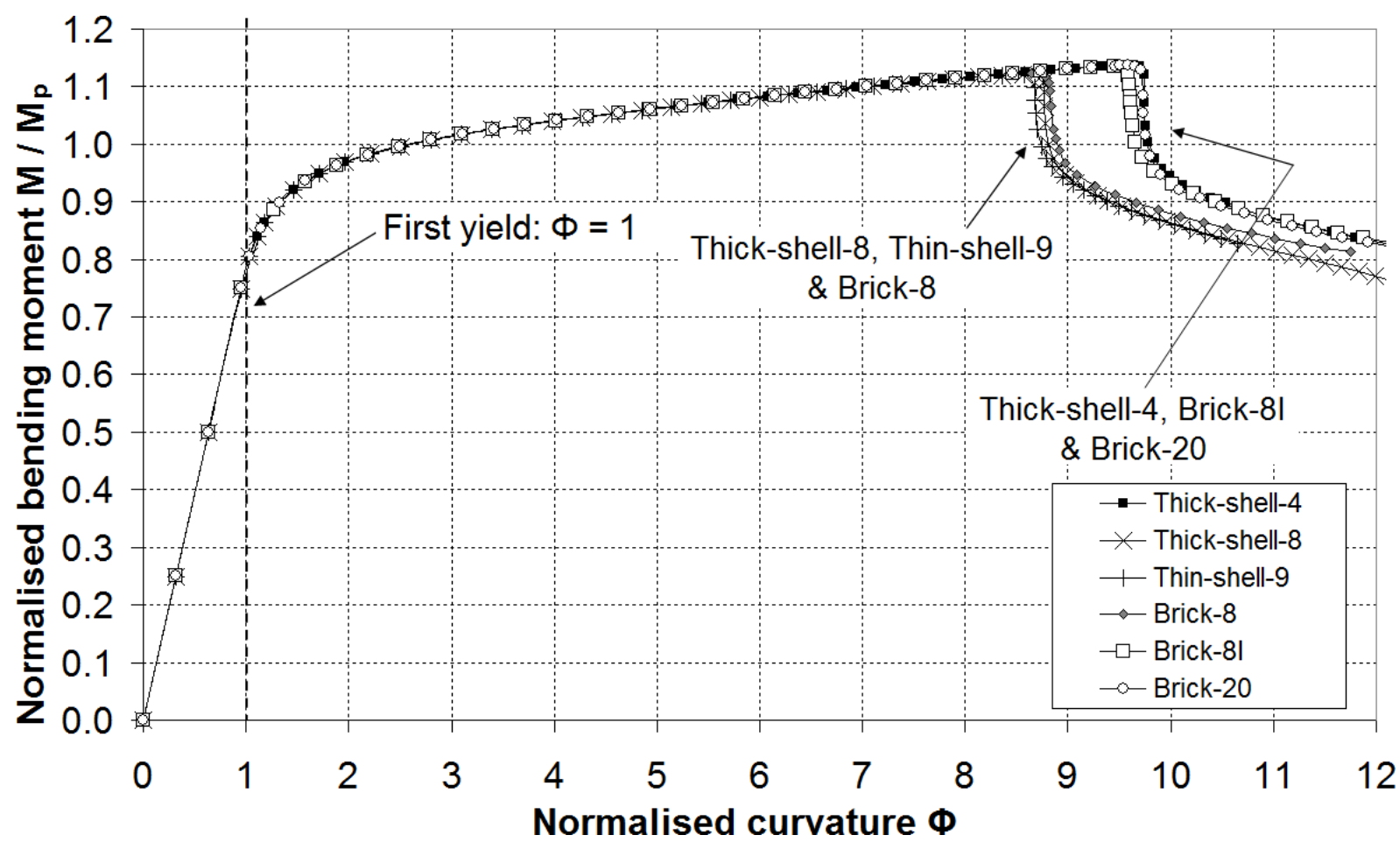

Fig. 12 - Normalised moment-curvature curves for $R / t=50$ 
Published in: International Journal of Mechanical Sciences, 74, 143-153.

DOI: http://dx.doi.org/10.1016/j.ijmecsci.2013.05.008

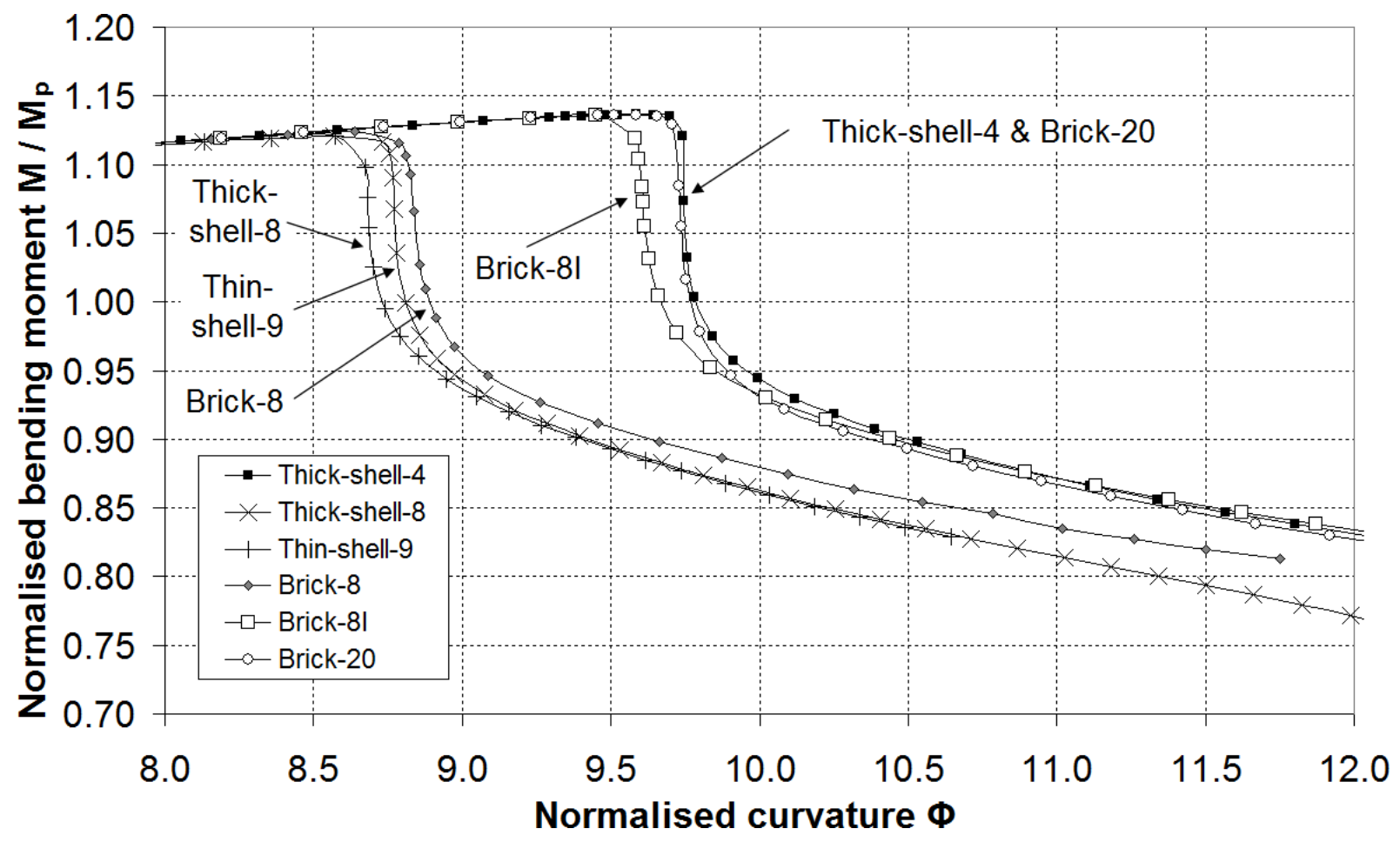

Fig. 13 - Normalised moment-curvature curves for $R / t=50$ : close up near bifurcation point

Solid continuum elements

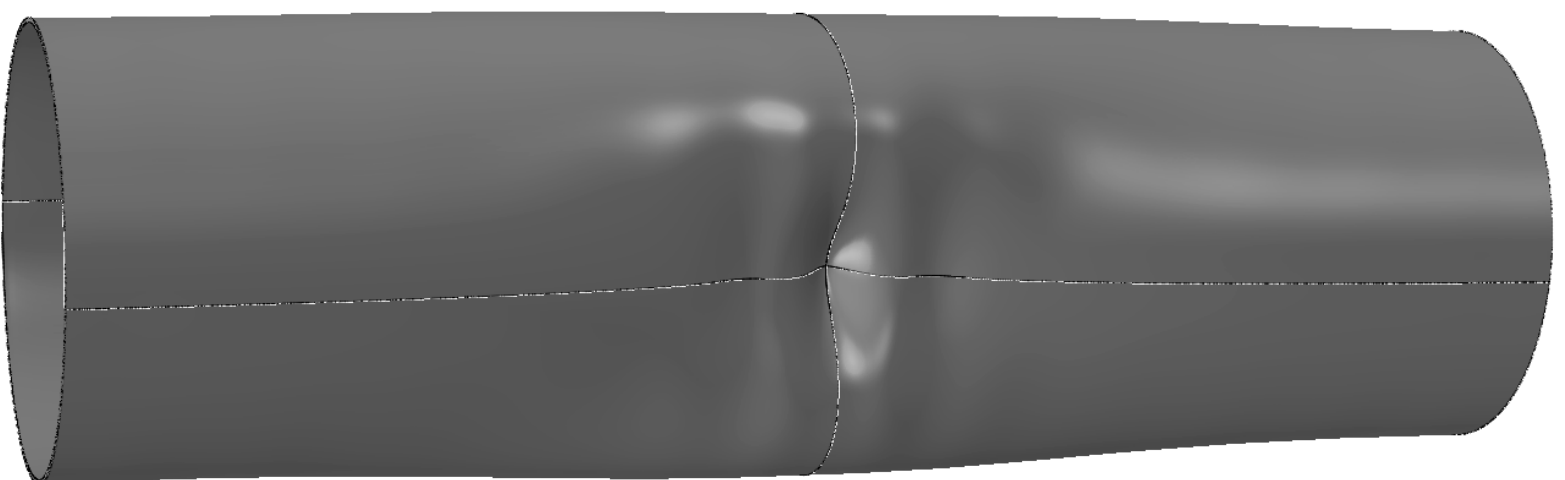

Shell elements

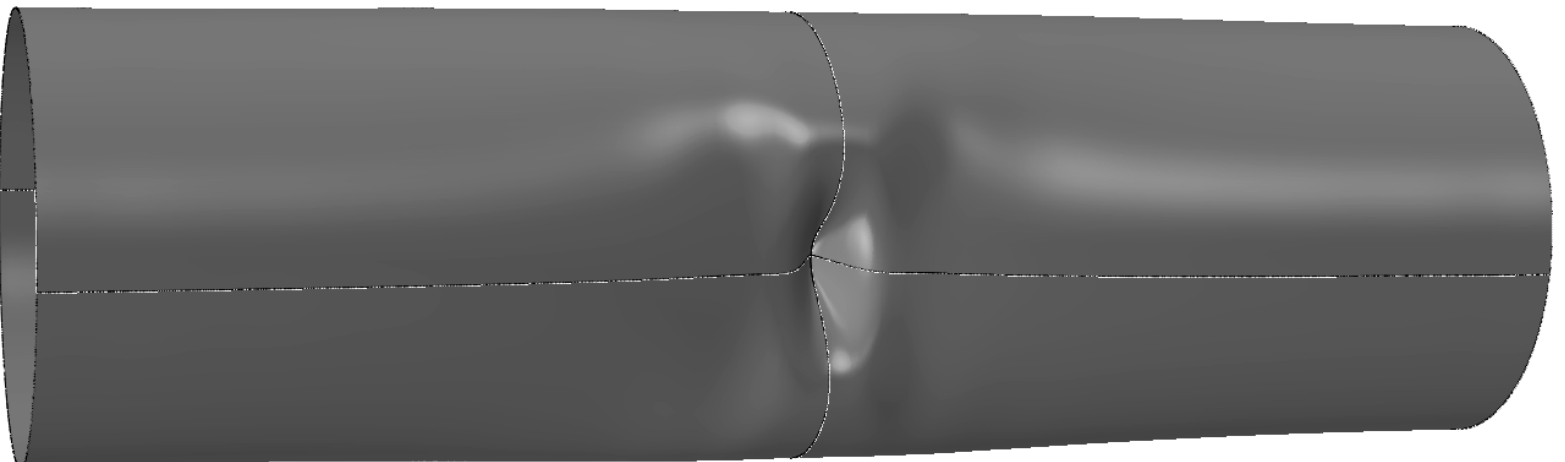

Fig. 14 - Predicted buckling modes for $R / t=50$ 
Published in: International Journal of Mechanical Sciences, 74, 143-153.

DOI: http://dx.doi.org/10.1016/j.ijmecsci.2013.05.008

The axial membrane strains at midspan follow the same circumferential variation for $R / t=50$ as for $R / t=25$ (Fig. 11) except that the peak compressive strain at the instant before bifurcation is now less than $2 \%$. The axial variation on the compressed generator at $\theta=0^{\circ}$ (Fig. 15) shows that plastic strains are low everywhere before buckling, the largest variation being caused by local shell bending at the end boundaries. However, the local curvatures associated with the axial wrinkling mode become significant in the post-buckling range. At a post-buckling moment of $0.9 M_{\mathrm{p}}$, the peak axial plastic strains reach $18 \%$ on the compressed outer surface, a value that depends on the element (Fig. 16). A finite strain formulation may thus be necessary if the model is required to explore ductility well into the post-buckling range and extensive plasticity is involved.

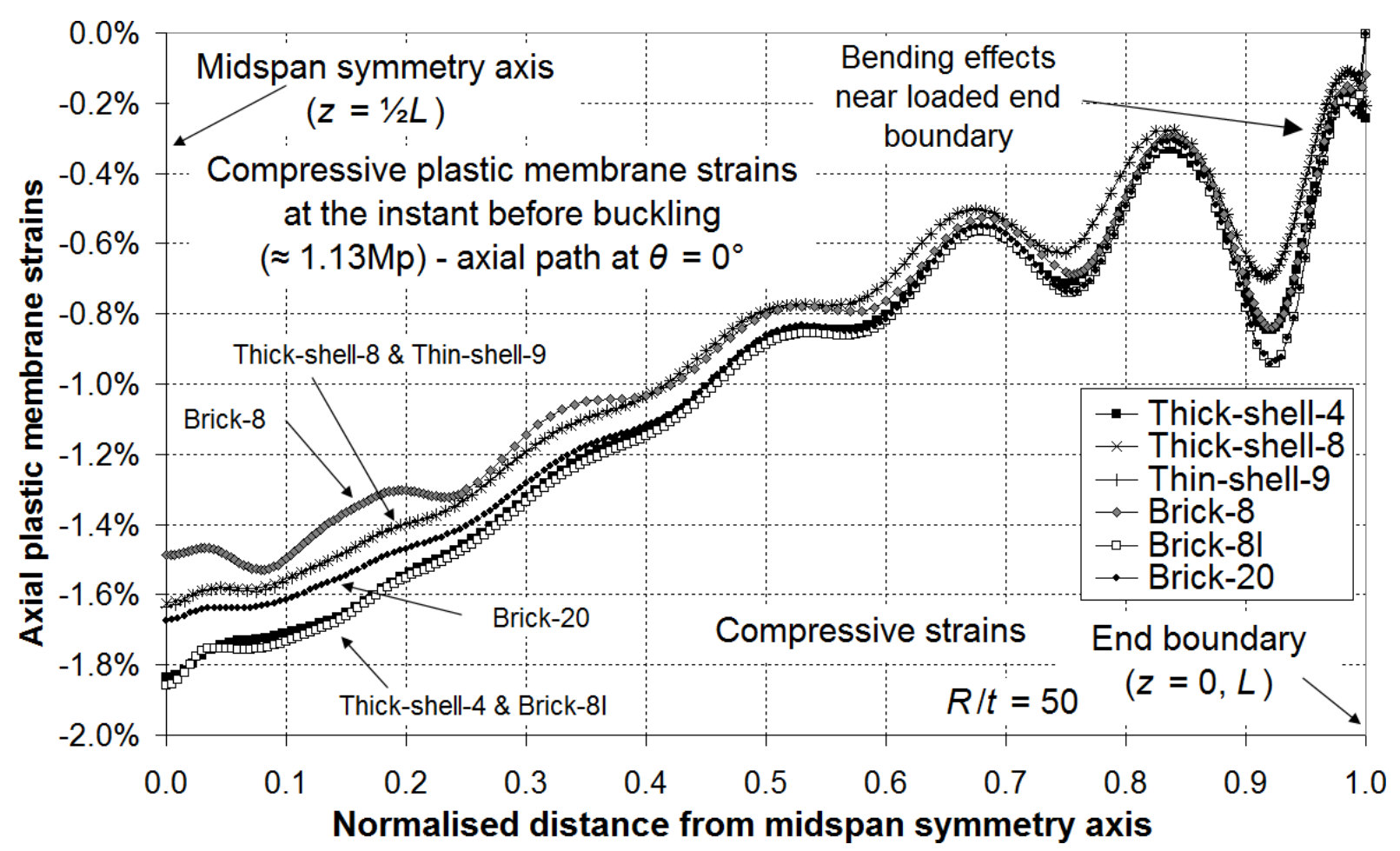

Fig. 15 - Axial plastic membrane strains at the instant before buckling through the axis of circumferential symmetry at $\theta=0^{\circ}$ for $R / t=50$ 
Published in: International Journal of Mechanical Sciences, 74, 143-153.

DOI: http://dx.doi.org/10.1016/j.ijmecsci.2013.05.008

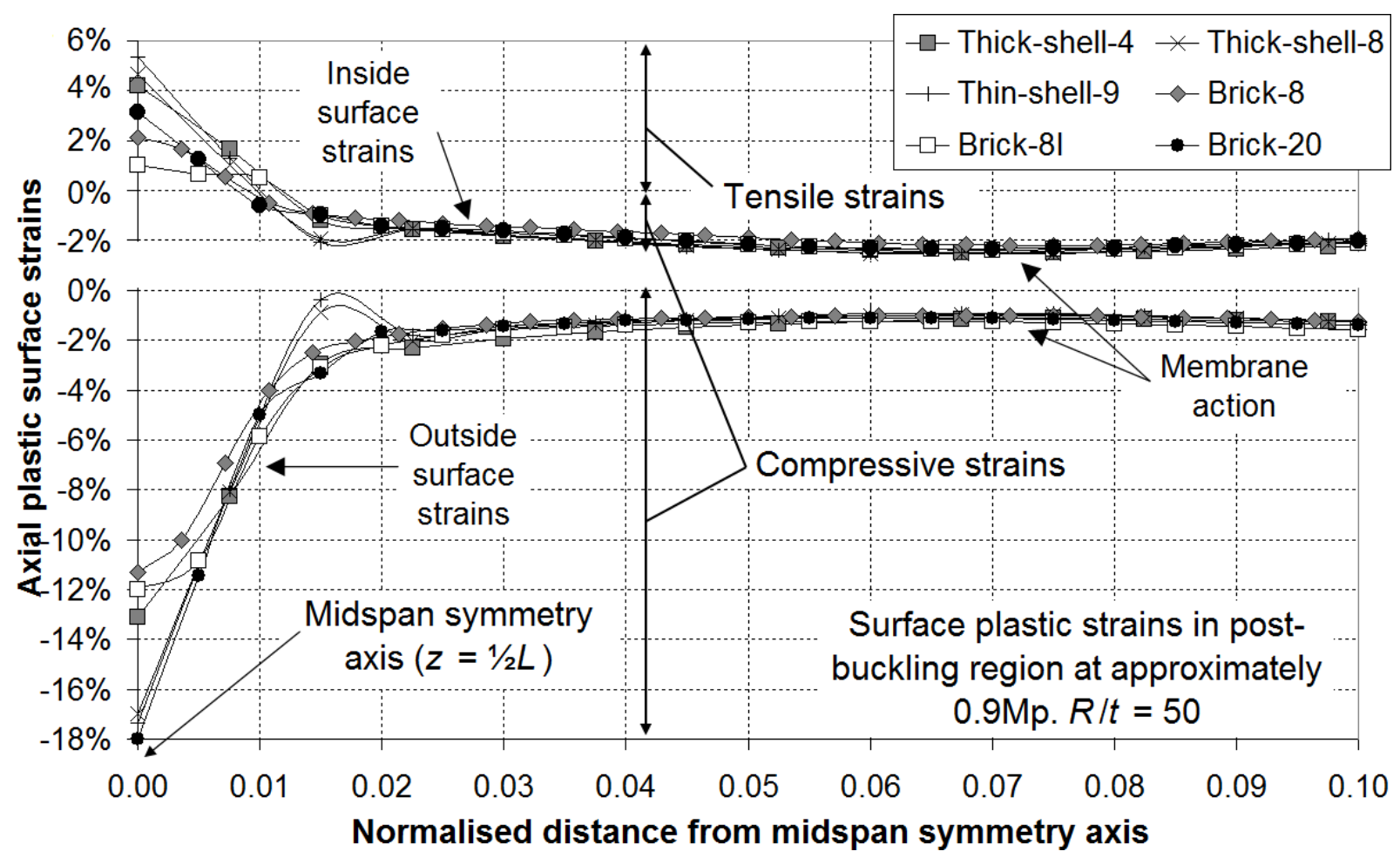

Fig. 16 - Axial plastic surface strains at approx. $0.9 M_{\mathrm{p}}$ in the post-buckling range on the most tensile and compressive generators for $R / t=50$

Table 5 - Buckling moments and selected mesh properties for $R / t=50$

\begin{tabular}{|c|c|c|c|c|c|c|}
\hline$R / t=50$ & Brick-8 & Brick-8I & Brick-20 & $\begin{array}{c}\text { Thick- } \\
\text { shell-4 }\end{array}$ & $\begin{array}{c}\text { Thick- } \\
\text { shell-8 }\end{array}$ & $\begin{array}{c}\text { Thin- } \\
\text { shell-9 }\end{array}$ \\
\hline $\begin{array}{c}\text { No. of elements } \\
\text { through wall thickness }\end{array}$ & 4 & 2 & 2 & $\mathrm{n} / \mathrm{a}$ & $\mathrm{n} / \mathrm{a}$ & $\mathrm{n} / \mathrm{a}$ \\
\hline Min. axial element size & $0.08 \sqrt{(R t)}$ & $0.16 \sqrt{ }(R t)$ & $0.16 \sqrt{(R t)}$ & $0.06 \sqrt{ }(R t)$ & $0.12 \sqrt{(R t)}$ & $0.12 \sqrt{(R t)}$ \\
\hline Max. axial element size & $0.25 \sqrt{ }(R t)$ & $0.31 \sqrt{ }(R t)$ & $0.31 \sqrt{ }(R t)$ & $0.31 \sqrt{ }(R t)$ & $0.37 \sqrt{(R t)}$ & $0.37 \sqrt{ }(R t)$ \\
\hline $\begin{array}{c}\text { Total no. of dofs } \\
\text { Buckling moment }\end{array}$ & $\mathbf{6 0 9 , 0 3 6}$ & 591,849 & 564,636 & 194,172 & 146,172 & 194,172 \\
\hline$M_{\mathrm{GMNA}} / M_{\mathrm{pl}}$ & & $\mathbf{1 . 1 2 4}$ & $\mathbf{1 . 1 3 6}$ & $\mathbf{1 . 1 3 6}$ & $\mathbf{1 . 1 2 1}$ & $\mathbf{1 . 1 2 1}$ \\
\hline
\end{tabular}

\section{Verification against experiments}

The preceding numerical investigations suggest that a shell element is suitable for the accurate modelling of cylindrical shells as thick as $R / t=10$ under global bending with extensive plasticity. A further set of numerical analyses were performed to verify the suitability of a shell treatment to reproduce selected results from the extensive 
Published in: International Journal of Mechanical Sciences, 74, 143-153.

DOI: http://dx.doi.org/10.1016/j.ijmecsci.2013.05.008

programme of experiments described by Kyriakides and $\mathrm{Ju}$ [41]. Eleven long aluminium 6061-T6 alloy cylindrical tubes with $R / t$ ratios between 9.75 and 30.25 were bent well into the plastic range. The material properties were deduced from measured uniaxial stress-strain curves and a Ramberg-Osgood relation of the form $\varepsilon=$ $(\sigma / E)\left(1+3 / 7\left(\sigma / \sigma_{y}\right)^{n-1}\right)$ was used to approximate the material. Tubes with $R / t=9.75$, 17.85 and 25 were chosen here for this verification, with $R / t=9.75$ being at the very thickest limit of the expected range of validity for shell models. The geometrical and material parameters of selected experiments of tubes are listed in Table 6. The predictions of the Thick-shell-4 element were additionally compared with those of the specialised shell finite element formulation described in the companion paper to the experimental study, $\mathrm{Ju}$ and Kyriakides [30], which employed small strain, finite rotation kinematic relations, $J_{2}$ plasticity theory and modelled the circular curvature of the shell exactly.
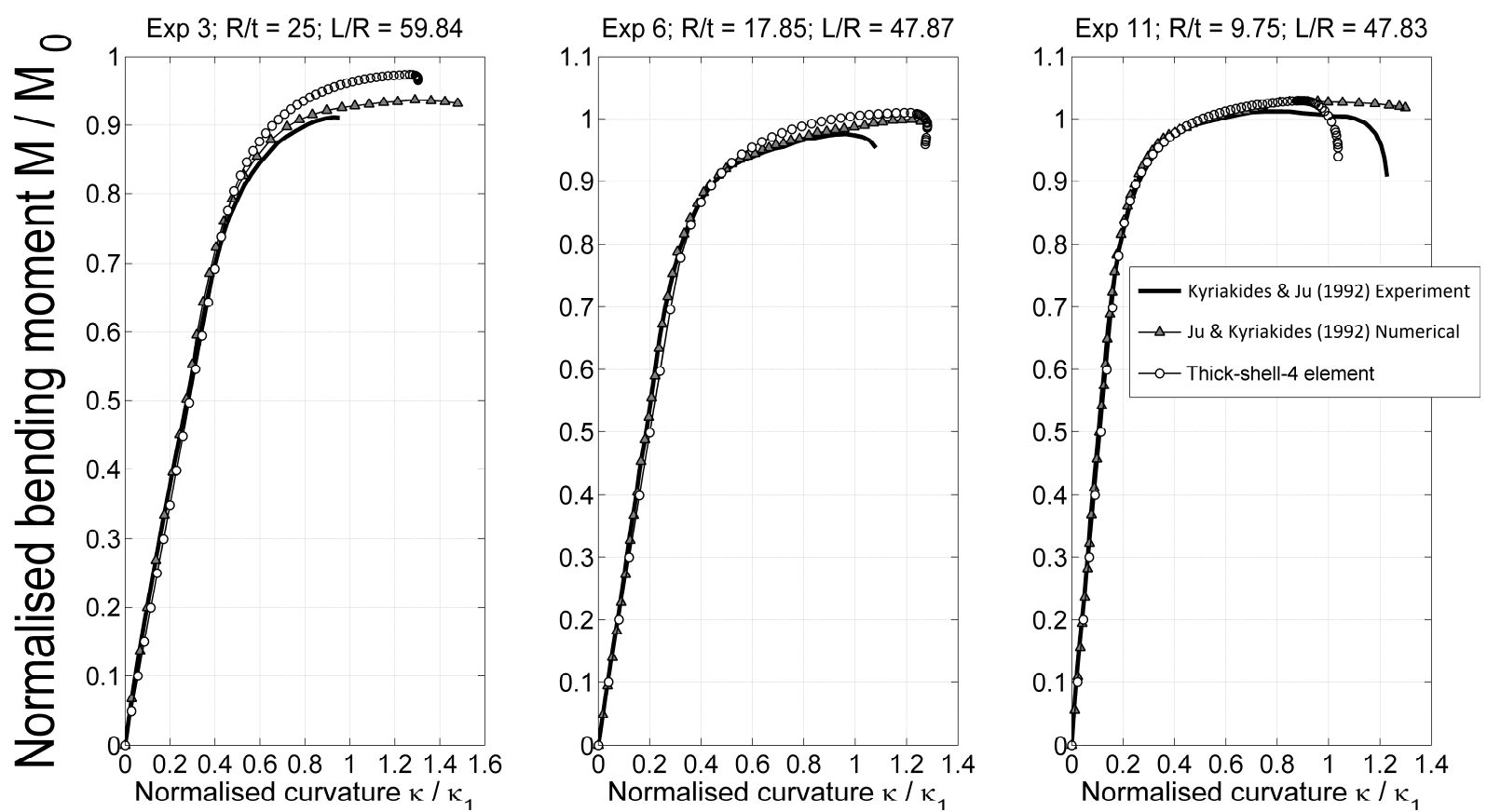

Fig. 17 - Numerical verification of selected experimental results of tubes in bending normalised moment-curvature plots 
Published in: International Journal of Mechanical Sciences, 74, 143-153.

DOI: http://dx.doi.org/10.1016/j.ijmecsci.2013.05.008
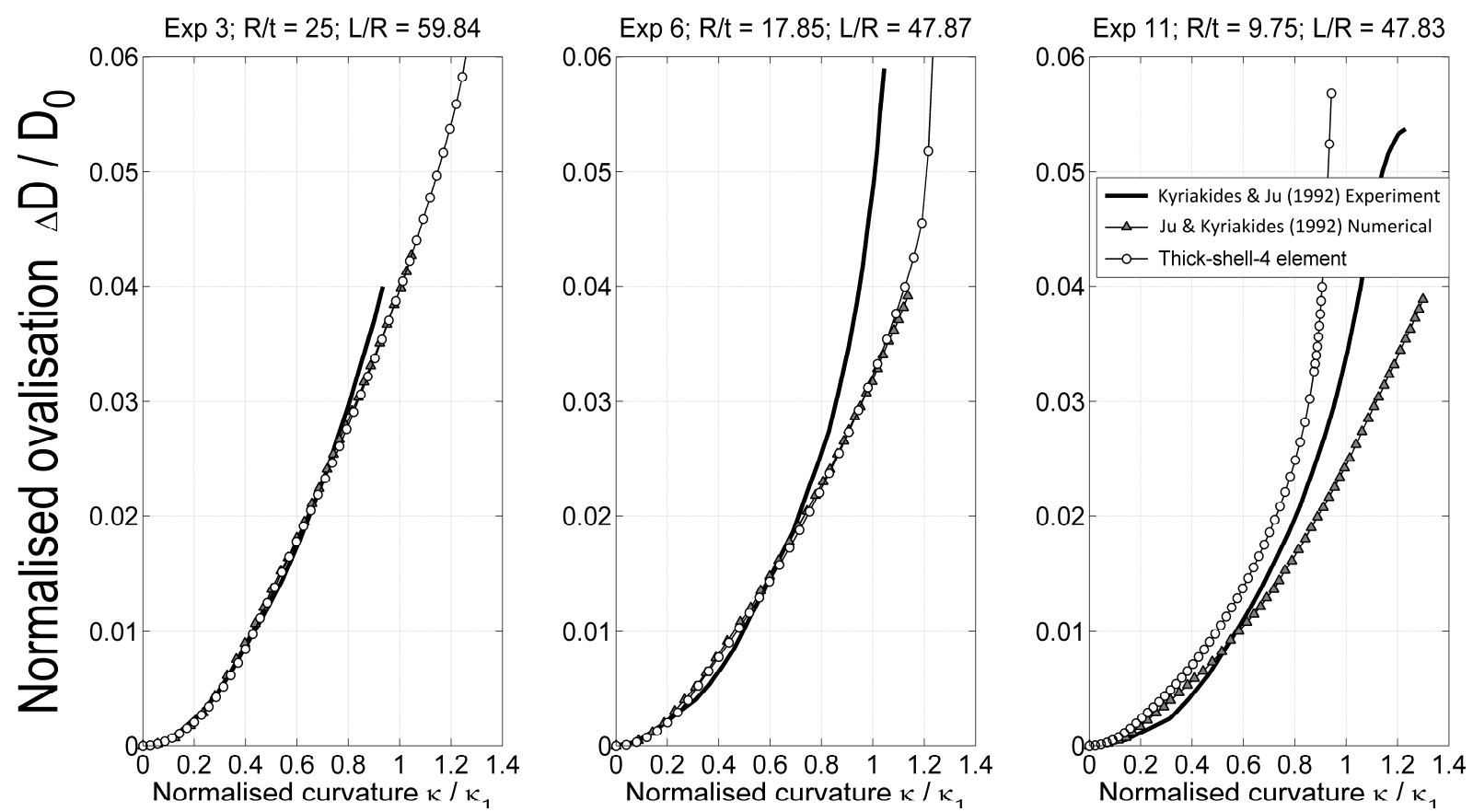

Fig. 18 - Numerical verification of selected experimental results of tubes in bending normalised ovalisation-curvature plots

Table 6 - Geometric and material characteristics of selected experiments from Kyriakides and $\mathrm{Ju}[41]$ assuming an aluminium alloy 6061-T6

\begin{tabular}{|c|c|c|c|c|c|c|}
\hline Experiment N. & $R / t$ & $L / R$ & $E(\mathrm{GPa})$ & $\sigma_{y}(\mathrm{MPa})$ & $\sigma_{0}(\mathrm{MPa})$ & Power $n$ \\
\hline 3 & 25.00 & 59.84 & 70.67 & 307.5 & 307.0 & 29 \\
\hline 6 & 17.85 & 47.87 & 67.36 & 282.0 & 283.4 & 28 \\
\hline 11 & 9.75 & 47.83 & 68.67 & 308.9 & 309.0 & 37 \\
\hline
\end{tabular}

The experimental and predicted relationships between the bending moment, mean tube curvature and ovalisation (Figs 17 and 18) have been normalised by the parameters $M_{0}$ $=\sigma_{0} D^{2} t$ and $\kappa_{1}=t / D^{2}$ respectively (see Table 6 for $\sigma_{0}$, the $0.2 \%$ proof stress), consistent with the notation of the original publication. The thick shell formulation exhibits a very good agreement with the experimental results for each tube, reproducing the ovalisation and buckling response accurately until deep into the plastic zone. In particular, the present predictions exhibit a remarkably close agreement with the numerical predictions of Ju and Kyriakides [30] for each tube except the very thickest one, $R / t=9.75$, for which neither formulation appears to predict the ovalisation response particularly well (Fig. 18) though the moment-curvature path is captured reasonably adequately. This suggests that a shell treatment is quite satisfactory for the 
Published in: International Journal of Mechanical Sciences, 74, 143-153.

DOI: http://dx.doi.org/10.1016/j.ijmecsci.2013.05.008

nonlinear buckling analysis of very thick cylindrical tubes with a complex material definition and extensive plasticity.

\section{Conclusions}

The following conclusions may be drawn from this study:

1) The classical literature is surprisingly vague about when a shell structure may be analysed using a thin shell theory approximation. Current advice is based on order-ofmagnitude assessments of analytical solutions to elastic problems that have relatively simple mechanics.

2) A thin shell treatment was found to give reasonably accurate estimates of the elasticplastic strain hardening buckling moment under uniform bending for cylinders as thick as $R / t=10$. However, this is insufficient to model the ductility of the response well, and in some cases this may also be an important criterion of failure. A thick shell treatment is more appropriate in such cases.

3) The predictions produced by a finite strain thick shell formulation were found to be of comparable accuracy to those produced by a solid continuum formulation for cylinders as thick as $R / t=10$. For such very thick cylinders, however, non-standard modelling techniques may need to be applied to ensure convergence. It is recommended that the second order or enhanced solid continuum elements are used to model such thick tubes.

4) It becomes uneconomical to use solid continuum elements for the analysis of uniform cylindrical tubes under global bending when $R / t \geq 25$, as several layers of such elements are necessary to correctly model the through-thickness bending at the end boundaries. Finite strain shell elements should be used instead, with no noticeable loss in accuracy. This conclusion may of course no longer be valid for the analysis of composite shells, which were not considered here. 
Published in: International Journal of Mechanical Sciences, 74, 143-153.

DOI: http://dx.doi.org/10.1016/j.ijmecsci.2013.05.008

5) Small strain shell elements may be applied with confidence for $R / t \geq 50$, except when the goal is to predict the ductility of the behaviour far into the post-buckling range.

6) The finite strain thick shell element was carefully verified against selected experimental results of tubes in bending as reported in Kyriakides and Ju [41]. The predictions exhibit a remarkably close agreement for tubes as thick as $R / t=9.75$. This suggests that thick shell elements may give realistic results even for very thick and long cylinders and that it is unnecessary to model such tubes using computationallyexpensive solid continuum elements or more specialised finite element formulations.

\section{Acknowledgements}

The authors would like to thank $\mathrm{Dr}$ Lei Chen who completed his $\mathrm{PhD}$ at The University of Edinburgh in 2011 and whose work laid much of the foundation and background to the material presented in this paper. The work itself was carried out as part of the EU Combitube research project funded by the European Commission, grant number RFSR-CT-2011-00034.

\section{References}

[1] Bushnell D. (1985). "Computerized buckling analysis of shells" Martinus Nijhoff Publishers.

[2] Donnell L.H. (1933). "Stability of thin-walled tubes under torsion" NACA Report No. 479 .

[3] Timoshenko S. P. (1953). "History of strength of materials" McGraw-Hill Book Company.

[4] Novozhilov V. V. (1964). "The theory of thin shells" Translation of the 2nd Russian edition by P.G. Lowe, ed J.R.M. Radok, P. Noordhoff Ltd, GroningenHolland.

[5] Calladine C. R. (1983). "Theory of shell structures" Cambridge University Press. 
Published in: International Journal of Mechanical Sciences, 74, 143-153.

DOI: http://dx.doi.org/10.1016/j.ijmecsci.2013.05.008

[6] Brush D.O. \& Almroth B.O. (1975). "Buckling of bars, plates and shells" McGrawHill.

[7] Seide P. (1975). "Small elastic deformations of thin shells" Noordhoff, Leyden, Holland.

[8] Reissner E. (1945). "The effect of transverse shear deformation on the bending of elastic plates" J. Appl. Mech, 12, A69-A77.

[9] Mindlin R. D. (1951). "Influence of rotary inertia and shear on flexural motions of isotropic elastic plates" J. Appl. Mech, 18, 31-38.

[10] Mushkelishvili N.I. (1953). "Some basic problems in the mathematical theory of elasticity" 3rd. Ed. P. Noordhoff Ltd., Groningen-Holland.

[11] Green A.E. \& Zerna W. (1968). "Theoretical elasticity" Oxford University Press.

[12] Timoshenko S. P. \& Goodier J.N. (1970). “Theory of Elasticity" McGraw-Hill International Editions.

[13] Ramm E. (2000). "From Reissner plate theory to three dimensions in large deformation shell analyses" ZAMM Zeitschrift für Angewandte Mathematik und Mechanik, 80(1), 61-68.

[14] Flügge W. (1975). “Statik und Dynamik der Schalen” Springer-Verlag.

[15] Timoshenko S. P. \& Woinowsky-Krieger S. (1959). "Theory of plates and shells" McGraw-Hill International Editions.

[16] Bushnell D. (1984). "Computerized analysis of shells - governing equations" Computers \& Structures, 18(3), 471-536. 
Published in: International Journal of Mechanical Sciences, 74, 143-153.

DOI: http://dx.doi.org/10.1016/j.ijmecsci.2013.05.008

[17] ABAQUS (2011). "ABAQUS Version 6.10.1” Dassault Systèmes Simulia Corp., Providence, RI, USA.

[18] Stephens W.B., Starnes J.H. Jr \& Almroth B.O. (1975). "Collapse of long cylindrical shells under combined bending and pressure loads" AIAA Journal, 13(1), 20-25.

[19] Gellin S. (1980). "The plastic buckling of long cylindrical shells under pure bending" International Journal of Solids and Structures, 10, 397-407.

[20] Kyriakides S. \& Shaw P.K. (1982). "Response and stability of elastoplastic circular pipes under combined bending and external pressure" Int. J. Solids and Structures, 18(11), 957-973.

[21] Shaw P.K. \& Kyriakides S. (1985). "Inelastic analysis of thin-walled tubes under cyclic bending” Int. J. Solids and Structures, 21(11), 1073-1100.

[22] Chen L., Doerich C. and Rotter J.M. (2008) "A study of cylindrical shells under global bending in the elastic-plastic range”, Steel Construction - Design and Research, Stahlbau, 1(1), 59-65.

[23] Brazier L. G. (1927). "On the flexure of thin cylindrical shells and other 'thin sections"” Proc. Roy. Soc. London Series A, 116, 104-114.

[24] Mathon C. \& Limam A. (2006). "Experimental collapse of thin cylindrical shells submitted to internal pressure and pure bending" Thin-Walled Structures $, 44,39-50$.

[25] Sherman D.R. (1976). "Test of circular steel tubes in bending" ASCE J. Struct. Div., 102(11), 2181-2195. 
Published in: International Journal of Mechanical Sciences, 74, 143-153.

DOI: http://dx.doi.org/10.1016/j.ijmecsci.2013.05.008

[26] Row D., Chan E. \& Langner C.G. (1987). "Prediction of pipe collapse under external pressure, axial load and bending" Offshore and arctic pipelines, J. S. Chung and K. Karal (eds), ASME, New York.

[27] Karamanos S.A. \& Tassoulas J.L. (1991). "Stability of inelastic tubes under external pressure and bending” ASCE J. of Eng. Mech., 117(12), 2845-2861.

[28] Seide P. \& Weingarten V.I. (1961). "On the buckling of circular cylindrical shells under pure bending" Journal of Applied Mechanics, 28(1), 112-116.

[29] Chen Y.N. \& Kempner J. (1976). "Buckling of oval cylindrical shells under compression and asymmetric bending" AIAA Journal, 14, 1235-1240.

[30] Ju G.T. \& Kyriakides S. (1992). "Bifurcation and localization instabilities in cylindrical shells under bending - II. Predictions" International Journal of Solids and Structures, 29(9), 1143-1171,

[31] Karamanos S.A. (2002). "Bending instabilities of elastic tubes" Int. J. Solids and Structures, 39, 2059-2085.

[32] Chen L. (2011). "Buckling of circular steel cylindrical shells under different loading conditions" PhD Thesis, The University of Edinburgh.

[33] Ades C.S. (1957). "Bending strength of tubing in the plastic range" $J$. Aeronautical Sci., 24, 605-610.

[34] Reissner E. (1959). "On finite bending of pressurised tubes" Journal of Applied Mechanics, ASME 26, 386-392.

[35] Axelrad E.L. (1965). "Refinement of buckling-load analysis for tube flexure by way of considering practical deformation" (Izvestiya Akademii Nauk SSSR, Otdelenie Teknicheskikh Nauk). Mekhanika i Mashinostroenie, 4, 133-139 (in Russian). 
Published in: International Journal of Mechanical Sciences, 74, 143-153.

DOI: http://dx.doi.org/10.1016/j.ijmecsci.2013.05.008

[36] Kempner J. \& Chen C.Y. (1974). "Buckling and initial post-buckling of oval cylindrical shells under combined axial compression and bending" Transactions of the New York Academy of Sciences, 171-191.

[37] Kedward K.T. (1978). "Nonlines collapse of thin-walled composite cylinders under flexural loading." Proceedings of the 2nd Int. Conf. on Composite Materials (Toronto), Metallurgical Society of AIME, Warrendale, PA, 353-365.

[38] Needleman A. (1982). "Finite elements for finite strain plasticity problems" In: Lee E.H., Mallet R.L. (eds), Plasticity of Metals at Finite Strain: Theory, Experiment and Computation. Rensselaer Polytechnic Institute, Troy, NY, 387-436.

[39] Hill R. (1950). "The mathematical theory of plasticity" Oxford University Press.

[40] Corona E. \& Kyriakides S. (1988). "On the collapse of inelastic tubes under combined bending and pressure" Int. J. Solids and Structures, 24(5), 505-535.

[41] Kyriakides S. \& Ju. G.T. (1992). "Bifurcation and localization instabilities in cylindrical shells under bending - I. Experiments" International Journal of Solids and Structures, 29(9), 1117-1142,

[42] Karamanos S.A. \& Tassoulas J.L. (1996a). "Tubular members. I: Stability analysis and preliminary results" ASCE J. of Eng. Mech., 122(1), 64-71.

[43] Karamanos S.A. \& Tassoulas J.L. (1996b). "Tubular members. II: Local buckling and experimental verification" ASCE J. of Eng. Mech., 122(1), 72-78.

[44] Houliara S. \& Karamanos S. A. (2006). "Buckling and post-buckling of long pressurised elastic thin-walled tubes under in-plane bending" International Journal of Nonlinear Mechanics, 41, 491-511. 
Published in: International Journal of Mechanical Sciences, 74, 143-153.

DOI: http://dx.doi.org/10.1016/j.ijmecsci.2013.05.008

[45] Houliara S. \& Karamanos S. A. (2010). "Stability of long transversely-isotropic elastic cylindrical shells under bending" International Journal of Solids and Structures, 47, 10-24.

[46] Jayadevan K.R., Østby E. \& Thaulow C. (2004). "Fracture response of pipelines subjected to large plastic deformation under tension" International Journal of Pressure Vessels and Piping, 81, 771-783.

[47] Østby E., Jayadevan K.R. \& Thaulow C. (2005). "Fracture response of pipelines subject to large plastic deformation under bending" Int. J. Pressure Vessels \& Piping, $82,201-215$.

[48] Corona E., Lee L-H \& Kyriakides S. (2006). "Yield anisotropy effects on bucking of circular tubes under bending" Int. J. Solids and Structures, 43, 7099-7118.

[49] Ramberg W. \& Osgood W.R. (1943). "Description of stress-strain curves by three parameters" National Advisory Committee on Aeronautics, Technical Note 902.

[50] Limam A., Lee-L-H \& Kyriakides S. (2010). "On the collapse of dented tubes under combined bending and internal pressure" International Journal of Mechanical Sciences, 55, 1-12.

[51] Limam A., Lee-L-H, Corona E. \& Kyriakides S. (2012). "Inelastic wrinkling and collapse of tubes under combined bending and internal pressure" International Journal of Mechanical Sciences, 52, 637-647.

[52] EN 1993-1-6 (2007). "Eurocode 3: design of steel structures, Part 1-6: strength and stability of shell structures." Comité Européen de Normalisation, Brussels.

[53] Riks E. (1979). "An incremental approach to the solution of snapping and buckling problems" Int. J. Solids. Struct., 15, 529-551. 
Published in: International Journal of Mechanical Sciences, 74, 143-153.

DOI: http://dx.doi.org/10.1016/j.ijmecsci.2013.05.008

[54] Timoshenko S.P. \& Gere J.M. (1961). "Theory of Elastic Stability", 2nd edn, McGraw-Hill, New York.

[55] Rotter J.M. (2004). "Buckling of cylindrical shells under axial compression" Chapters and 2 in Buckling of Thin Metal Shells, Eds J.G. Teng \& J.M. Rotter, Spon, London, 1-87.

[56] Batoz J.L., Bathe K.J. \& Ho L.W. (1980). "A study of three-node triangular plate bending elements" International Journal for Numerical Methods in Engineering, 15, 1771-1821.

[57] Cook R.D., Malkus D.S., Plesha M. E. \& Witt R.J. (2002). "Concepts and applications of finite element analysis" 4th Ed., John Wiley \& Sons.

[58] Simo J.C. \& Rifai M.S. (1990). "A class of assumed strain methods and the methods of incompatible modes" International Journal for Numerical Methods in Engineering, 29, 1595-1638.

[59] Simo J.C. \& Armero F. (1992). "Geometrically nonlinear enhanced strain mixed methods and the method of incompatible modes" International Journal for Numerical Methods in Engineering, 33, 1413-1449.

[60] Agah-Tehrani A, Lee E. H., Mallett R. L. \& Onat E.T. (1986). "The theory of elastic-plastic deformation at finite strain with induced anisotropy modelled as combined isotropic-kinematic hardening" Metal Forming Report, Rensselaer Polytechnic Institute, Troy, New York.

[61] Zienkiewicz O.C., Taylor R.L. \& Too J.M. (1971). "Reduced integration technique in general analysis of plates and shells" IJNME 3, 275-290.

[62] Laulusa A., Bauchau O.A., Choi J.Y., Tan V.B.C. \& Li L. (2005). "Evaluation of some shear deformable shell elements" Int. J. Solids and Structures, 43, 5033-5054. 
Published in: International Journal of Mechanical Sciences, 74, 143-153.

DOI: http://dx.doi.org/10.1016/j.ijmecsci.2013.05.008

[63] Schafer B.W., Li Z. \& Moen C.D. (2010). "Computational modelling of coldformed steel" Thin-Walled Structures, 48, 752-762.

[64] MacNeal R. (1994). "Finite Elements: Their Design and Application" Marcel Dekker, New York.

[65] Song C.Y., Teng J.G. \& Rotter J.M. (2004). "Imperfection sensitivity of thin elastic cylindrical shells subject to partial axial compression" International Journal of Solids and Structures, 41, 7155-7180.

[66] Gardner L. \& Nethercot D.A. (2004). "Numerical modelling of stainless steel structural components - a consistent approach" ASCE Journal of Structural Engineering, 130(10), 1586-1601.

[67] Panasz P. \& Wisniewski K. (2008). "Nine-node shell elements with 6 dofs/node based on two-level approximations. Part I Theory and linear tests" Finite Elements in Analysis and Design, 44, 784-796.

[68] Moen C.D. \& Schafer B.W. (2009). "Elastic buckling of thin plates with holes in compression or bending" Thin-Walled Structures, 47, 1597-1607.

[69] Budiansky B. \& Sanders J.L. (1963). "On the 'best' first-order linear shell theory" Progress in Applied Mechanics, The Prager Anniversary Volume, Macmillan, London, 129-140.

[70] Bathe K.J., Ramm E. \& Wilson E.L. (1975). "Finite element formulations for large deformation dynamic analysis." International Journal for Numerical Methods in Engineering, 9(2), 353-386.

[71] Ramm E., Braun M. \& Bischoff M. (1995). "Higher order nonlinear shell formulations: theory and applications" Journal of the International Association for Shell and Spatial Structures, 36(119), 145-152. 
Published in: International Journal of Mechanical Sciences, 74, 143-153.

DOI: http://dx.doi.org/10.1016/j.ijmecsci.2013.05.008

[72] Bischoff M. \& Ramm E. (1997). "Shear deformable shell elements for large strains and rotations" International Journal for Numerical Methods in Engineering, 40(23), 4427-4449.

[73] Neal B.G. (1963). "The plastic methods of structural analysis" Chapman and Hall.

[74] Bruneau M., Ung C.M. \& Whittaker A. (1998). "Ductile design of steel structures" McGraw Hill.

[75] Yamaki N. (1984). "Elastic Stability of Circular Cylindrical Shells", North Holland, Elsevier Applied Science Publishers, Amsterdam.

[76] Rotter J.M. \& Teng J.G. (1989). "Elastic stability of cylindrical shells with weld depressions" ASCE Journal of Structural Engineering, 115(5), 1244-1263.

[77] Heyman J. (1977). "Equilibrium of shell structures" Oxford University Press.

\section{FIGURE CAPTIONS}

Fig. 1 - Qualitative illustration of the equilibrium paths in cylinders with $L / R=7$ and a strain hardening material law (cylinders of different length exhibit similar qualitative features)

Fig. 2 - Assumed engineering stress-strain relation, with $2.5 \%$ linear strain hardening

Fig. 3 - Features of the numerical model for both shell and solid elements

Fig. 4 - Normalised moment-curvature curves for $R / t=10$

Fig. 5 - Normalised moment-curvature curves for $R / t=10$ : close-up near limit point

Fig. 6 - Predicted buckling modes for $R / t=10$ 
Published in: International Journal of Mechanical Sciences, 74, 143-153.

DOI: http://dx.doi.org/10.1016/j.ijmecsci.2013.05.008

Fig. 7 - Illustration of the effect of ovalisation for $R / t=10$

Fig. 8 - Normalised moment-curvature curves for $R / t=25$

Fig. 9 - Normalised moment-curvature curves for $R / t=25$ : close up near limit point

Fig. 10 - Predicted buckling modes for $R / t=25$

Fig. 11 - Axial plastic membrane strains at the instant of buckling through the axis of axial symmetry $(1 / 2 L-$ midspan$)$

Fig. 12 - Normalised moment-curvature curves for $R / t=50$

Fig. 13 - Normalised moment-curvature curves for $R / t=50$ : close up near bifurcation point

Fig. 14 - Predicted buckling modes for $R / t=50$

Fig. 15 - Axial plastic membrane strains at the instant before buckling through the axis of circumferential symmetry at $\theta=0^{\circ}$ for $R / t=50$

Fig. 16 - Axial plastic surface strains at approx. $0.9 M_{\mathrm{p}}$ in the post-buckling range on the most tensile and compressive generators for $R / t=50$

Fig. 17 - Numerical verification of selected experimental results of tubes in bending normalised moment-curvature plots

Fig. 18 - Numerical verification of selected experimental results of tubes in bending normalised ovalisation-curvature plots

\section{TABLE CAPTIONS}


Published in: International Journal of Mechanical Sciences, 74, 143-153.

DOI: http://dx.doi.org/10.1016/j.ijmecsci.2013.05.008

Table 1 - Selected 3D solid continuum finite element formulations with ABAQUS implementations

Table 2 - Selected 3D structural shell finite element formulations with ABAQUS implementation

Table 3 - Buckling moments and selected mesh properties for $R / t=10$

Table 4 - Buckling moments and selected mesh properties for $R / t=25$

Table. 5 - Buckling moments and selected mesh properties for $R / t=50$

Table 6 - Geometric and material characteristics of selected experiments from Kyriakides and Ju [41] assuming an aluminium alloy 6061-T6 